Discussion

Papers



Do Expert Panelists Herd? Evidence from FDA Committees 
Opinions expressed in this paper are those of the author(s) and do not necessarily reflect views of the institute.

IMPRESSUM

(C) DIW Berlin, 2019

DIW Berlin

German Institute for Economic Research

Mohrenstr. 58

10117 Berlin

Tel. +49 (30) $89789-0$

Fax +49 (30) $89789-200$

http://www.diw.de

ISSN electronic edition 1619-4535

Papers can be downloaded free of charge from the DIW Berlin website:

http://www.diw.de/discussionpapers

Discussion Papers of DIW Berlin are indexed in RePEc and SSRN:

http://ideas.repec.org/s/diw/diwwpp.html

http://www.ssrn.com/link/DIW-Berlin-German-Inst-Econ-Res.html 


\title{
Do Expert Panelists Herd? Evidence from FDA Committees ${ }^{* \dagger}$
}

\author{
Melissa Newham ${ }^{\ddagger} \quad$ Rune Midjord ${ }^{\S}$
}

First Version: June 2018

This Version: May 2020

\begin{abstract}
We develop a structural model to address the question whether, and to what extent, expert panelists engage in herd behavior when voting on important policy questions. Our data comes from FDA advisory committees voting on questions concerning the approval of new drug applications. We utilize a change in the voting procedure from sequential to simultaneous voting to identify herding. Estimates suggest that around half of the panelists are willing to vote against their private assessment if votes from previous experts indicate otherwise and, on average, 9 percent of the sequential votes are actual herd-votes. Temporary committee members are more prone to herding than regular (standing) members. We find that simultaneous voting improves information aggregation given our estimates.
\end{abstract}

JEL-codes: D72, D82, D83, D91, I10, I18.

Key words: Herd behavior, expert committees, structural estimation, FDA, public health

${ }^{*}$ The authors contributed equally to this paper. We thank Albert Banal-Estanol, Kai Barron, Nuria Boot, Federico Ciliberto, Tomaso Duso, Florian Ederer, Philip Haile, Vardges Levonyan, Tomás Rodríguez Barraquer, Nicolas de Roos, Fiona Scott Morton, Jo Seldeslachts, Timothy Simcoe, Peter Norman Sørensen, Jean Tirole, Otto Toivanen, Hannes Ullrich, Justin Valasek, Frank Verboven, Georg Weizsäcker and Christoph Wolf for helpful comments. We further thank seminar participants at DIW Berlin, the University of Virginia, Yale University, the University of Zürich, the Spring Meeting of Young Economists and CEPR for valuable comments and suggestions.

${ }^{\dagger}$ An earlier version of this paper circulated under the title, "Herd Behavior in FDA Committees: A Structural Approach"

${ }^{\ddagger}$ Corresponding author: KU Leuven and DIW Berlin. KU Leuven, Faculty of Economics and Business, Naamsestraat 69, 3000 Leuven, Belgium. Tel: 003216374581 (melissa.newham@kuleuven.be)

${ }^{\S}$ Copenhagen Business School, Department of Economics (rm.eco@cbs.dk) 


\section{Introduction}

Many important decisions within public and private organizations are based on recommendations from expert committees. Advisory boards give strategic advice to the management of corporations and expert committees recommend on issues such as climate, national security, education, and medical drugs. ${ }^{1}$ The main advantage of expert committees is their ability to aggregate multiple sources of information and hence allow for more informed decisions. A common way to gauge the information held by individual committee members is to have a sequential vote (by roll call or going stepwise around the committee table). For example, roll call voting is used by committees of the European Parliament and it is one of the official voting procedures for advisory committees under the United Nations. In the United States, roll call voting is often used by advisory committees under city and town councils and occasionally by committees at the federal level. ${ }^{2}$ When committee members vote sequentially, the information contained in the vote will be affected, and possibly diluted, if members engage in herd behavior (i.e. if they are swayed by observing the preceding votes). To this end, it is crucial to know whether, and to what extent, expert panelists engage in herd behavior and how this affects information aggregation.

In this paper, we develop a structural model to estimate the prevalence of informational herding (see Banerjee, 1992; Bikhchandani, Hirshleifer, and Welch, 1992; Welch, 1992; Smith and Sørensen, 2000) and investigate its consequences for information aggregation in the U.S. Food and Drug Administration's (FDA) advisory committees. While other papers have studied herding in different empirical settings ${ }^{3}$ and laboratory experiments, ${ }^{4}$ this is the first paper to estimate a model of herd behavior in advisory committees. Moreover a change in the voting procedure for FDA committtees from sequential to simultaneous

\footnotetext{
${ }^{1}$ In 2006 the United States government maintained 916 federal advisory committees composed of 67,346 members (Brown, 2009).

${ }^{2}$ For example, the advisory committees under the Federal Communications Commission and the Health Resources and Services Administration.

${ }^{3}$ To mention a few: presidential primaries (Knight and Schiff, 2010), restaurant dining (Cai, Chen, and Fang , 2009), investment recommendations (Graham, 1999), stock market trading (Cipriani and Guarino, 2014), financial decisions (Bursztyn et al., 2014), movie sales (Moretti, 2011), and movie reviews (Camara and Dupuis, 2014).

${ }^{4}$ See Anderson and Holt (1997) for an early reference and Weizsäcker (2010) for a meta analysis.
} 
voting in 2007 provides a remarkably "clean" natural experiment which we take advantage of to identify herd behavior.

The drug approval decisions made by FDA affect millions of users; if beneficial drugs do not win approval patients miss the opportunity of improved medication and if bad drugs are approved the consequences can be fatal. ${ }^{5}$ To assist in making difficult approval decisions, the FDA makes use of advisory committees. The committees consist of around a dozen medical experts who vote in a fixed order on yes/no questions related to drug approvals, for example, "Should omapatrilat be approved for the treatment of hypertension?" In 2007 the FDA changed the voting procedure for their advisory committees from sequential to simultaneous voting citing concerns of "momentum" effects in sequential voting where some sequential voters may be influenced by the preceding votes, especially if those votes signal a clear trend. ${ }^{6}$

Our data is gathered from verbatim transcripts of FDA committee meetings held between 1996 and 2014 and comprises 10,466 votes from 1,378 unique individuals. We have data from a total of 813 voting questions, of which roughly half take place under sequential voting. Data on individual experts includes their educational background, gender and "voter category." FDA committees operate with four categories of voting members. Regular (standing) members serve four-year terms and have recognized expertise in a relevant field. Additional experts are usually added as temporary voting members. Like regular members, temporary members have expertise in a relevant field. Each committee also has a qualified consumer and a patient representative as voting members.

In our model, committee members vote on independent yes/no questions e.g. whether the benefits of a new drug outweigh the risks. For each voting question, there is a common prior on the correct answer (the state) being "yes." The prior contains relevant public

\footnotetext{
${ }^{5}$ One of the most debated FDA decisions is the approval of the painkiller Vioxx (nytimes.com/topic/subject/vioxx-drug). According to Graham et al. (2005) Vioxx caused an estimated 88.000 to 140.000 excess cases of serious heart disease in the U.S. over its market life.

6 "There has been much discussion inside and outside FDA regarding sequential versus simultaneous voting...scholars and social scientists have studied the risk of "momentum" in sequential voting, exploring whether some sequential voters may be influenced, perhaps even subconsciously, by the votes that precede theirs, especially if those votes are nearly identical or signal a clear trend. [footnote reference to Banerjee (1992) and Callander (2007)]." In Draft Guidance for FDA Advisory Committee Members and FDA Staff: Voting Procedures for Advisory Committee Meetings (2007).
} 
information on the question at hand including committee discussions and presentations leading up to the voting stage. On top of this, each expert receives a private signal about the state which depends on the precision of private information and the true state. In this respect, each panelist draws on his/her unique experience, intuition, and analytical skills. In the empirical implementation, we allow for the general precision of the continuous signals to vary across committee members with certain observable characteristics (e.g. educational background and voter category) and recover estimates for members' ability.

There are two types of committee members in our model. The herd type uses public information, his/her private signal, and the vote-history to update beliefs about the state and votes "yes" if, and only if, the updated beliefs exceed his/her standard of proof for voting yes. If the vote history is dominated by "yes" votes the herd type intuitively updates in a way that favors the "yes" state. However, the order in which the votes are placed matters for the belief updating and if a few "no" votes are the most recent ones and come from members with high expertise then the belief updating may actually favor the "no" state. By contrast, the expressive type considers only public information and his/her private signal (ignoring any preceding votes) when casting his/her vote. ${ }^{7} \mathrm{~A}$ member's type is private information. In one version of the model we assume herd types are fully Bayesian and take into consideration the probability that committee members before them are also herd types, in another version we assume that they are "naïve" and believe that all preceding votes come from expressive types (following Eyster and Rabin, 2010). We estimate the proportion of herd types and members' standards of proof, allowing these parameters to vary with observable characteristics.

The problem empiricists face when seeking to measure herd behavior is that private information is not observable so it is difficult to tell when agents have altered their behavior due to observing the actions of others. In many contexts, decisions may be clustered for reasons other than herding. For example, in our context, if a drug is clearly a good drug then we expect many experts will vote in favor of the drug. The structural approach

\footnotetext{
${ }^{7}$ Our model is a model of statistical herding with expressive types added. A closely related concept is reputational herding where agents are motivated by appearing to be well informed about the state i.e. having strong private signals (see Ottaviani and Sørensen (2001) for a model of reputational concerns in committees).
} 
allows us to separate the confounding effects of members' inclination to herd, their level of expertise, their degree of cautiousness (standard of proof required to vote in favor of a drug) and the strength of the common prior.

To identify the model's parameters we rely on the fact that we observe committee members voting across multiple voting questions and make use of information on the exact sequence of votes under sequential voting to identify herd voting. Importantly, the natural experiment allows us to observe voting outcomes when herd behavior can be ruled out. Intuitively, herding tends to make committee members follow the votetrend under sequential polling which makes, all else equal, unanimous outcomes more frequent than absent any herding. However, high precision of the committee members private information also makes unanimous vote outcomes more common. Having access to simultaneous data allows us to get a grip on key parameters of the model, like the precision of members' private information, when there is no herding at play.

Our results suggest that experts voting on important questions relating to drug approvals are indeed susceptible to herd behavior. On average, the proportion of herd types is close to one half ( $48 \%$ in the Bayesian updating version and $52 \%$ in the naïve updating version) i.e. around half of the expert panelists take into account, and are potentially swayed by, the votes that precede theirs. Interestingly, the share of herd types is considerably larger among temporary members than regular members.

The presence of herd types gives rise to the possibility of "herd votes" i.e. when a herd type votes yes (no) whereas had he/she not observed the vote history he/she would have voted no (yes). Using our model to simulate voting under the two regimes, we find that on average around $9 \%$ of the sequential votes are herd votes i.e. cases where members actually change their vote from what it would have been if they had ignored the vote history. This level of herding in the simulated data generates patterns in line with what we see in the real data, namely that the share of unanimous vote outcomes increases markedly under sequential voting.

Our estimates on the accuracy of the committee members private information are relatively high; on average private signals go in the wrong direction only around 20 percent 
of the time. Regular members have the most accurate private information whereas the signals of consumer and patient representatives are less precise. In general, the committee members are slightly cautious, meaning that it takes more than the preponderance of evidence for a committee member to vote "yes." Consumer representatives are particularly cautious and at the other end of the spectrum patient representatives are neither cautious or incautious.

We next consider the consequences of herding on information aggregation. Although simultaneous voting is not informationally efficient for all parameter values of our model, we find that switching to simultaneous voting improves the probability that the committee's assessment matches the state; where the effect is larger if we assume committee members apply naïve updating. Additionally, we use our model to demonstrate that the detrimental consequences of herding are exacerbated when information is less precise. Our main policy implication is therefore to follow the example of the FDA and substitute sequential "go-around" voting with simultaneous (electronic) voting.

Our model and estimation approach is inspired by the methodology in Cipriani and Guarino (2014) which serves as the first paper to estimate herd behavior with a structural model. In their application they estimate herd behavior in financial markets using transaction data from a publicly traded stock. Herding can occur over the course of a day due to uncertainty about whether an informational event has occurred and whether the fundamental value of the stock has increased or decreased. In their model, a market maker interacts with the sequence of traders and sets the price of the asset. Our model simplifies this framework by dispensing with the market maker and price mechanism. On the other hand, we incorporate heterogeneity regarding priors, signals and preferences, and develop a version of the model with naïve updating. Furthermore, we make use of data generated through simultaneous voting whereas in Cipriani and Guarino (2014) all transaction data is assumed to be generated sequentially.

By using a structural model to explain individual committee members' behavior, this paper also draws on the framework put forward in Iaryczower and Shum (2012). They explain decision-making in the U.S. Supreme Court by taking into account differences in 
the bias or ideology of justices, the information available to the justices and their ability to apply the law to the specifics of the case. Further research in this tradition includes Hansen, McMahon, and Rivera (2014) who explain individual voting behavior on the Bank of England's Monetary Policy Committee and Camara and Kyle (2016) who estimate a voting model to recover FDA committee members' skill and bias associated with financial ties. Iaryczower, Shi, and Shum (2018) use a structural model to quantify the effect of deliberation on the decisions of US appellate courts. Whereas Iaryczower, Shi, and Shum (2018) study the effect of deliberation before voting, we consider voting after collective discussions have taken place.

The FDA's reform of voting procedure in 2007 has been examined in a case study by Urfalino and Costa (2015). They collect data from six committees (202 voting questions) from 2003 to 2010 and report the proportion of unanimous, strong majority, and majority outcomes. Urfalino and Costa (2015) show that under simultaneous voting the proportion of unanimous outcomes is lower while the proportion of strong majority outcomes is higher. The authors suggest that these changes are due to reduced expert conformity following the shift to simultaneous voting. We extend this analysis in our descriptive and reduced-form section.

The rest of the paper is organized as follows. In Section 2 we introduce the theoretical model. Section 3 describes the data. Section 4 undertakes a descriptive and reducedform (regression) analysis. In Section 5 we describe the estimation procedure and Section 6 discusses the main results. Section 7 considers information aggregation. Section 8 concludes.

\section{Model}

We consider advisory committees voting on various yes/no questions. As in the case with FDA committees, we can think of expert panelists polling on issues regarding a specific application, proposal, or scientific question. There are $J$ voting questions and a generic voting question is denoted by $j \in\{1, \ldots, J\}$. For each voting question, $j$, there is a common unobserved state $\theta^{j} \in\{0,1\}$ that equals 1 if the correct answer to question $j$ 
is "yes" and 0 if the correct answer to question $j$ is "no." The state is independently drawn across the $J$ voting questions. Let $\mu_{0}^{j} \in(0,1)$ indicate the common prior belief that $\theta^{j}=1$. The common prior contains relevant public information including committee discussions leading up to the voting stage. The number of voting members on question $j$ is $N^{j} \geq 2$ and we denote the vote from committee member $i^{j} \in\left\{1^{j}, \ldots, N^{j}\right\}$ by $v_{i}^{j} \in\{1,0\}$, where $v_{i}^{j}=1$ is a "yes" vote and $v_{i}^{j}=0$ is a "no" vote.

Voting procedure. The voting procedure on question $j$ can be either sequential or simultaneous. If voting on question $j$ is sequential, then the panelists vote sequentially and openly in an exogenously given order. The voting order is such that committee member $i^{j}$ votes as the $i$ 'th person (i.e. member $1^{j}$ votes first, then member $2^{j}$, etc.). Let $h_{i}^{j} \equiv v_{1}^{j}, \ldots, v_{i-1}^{j}$ denote the voting history observable for member $i^{j}$ where $h_{1}^{j}=\{\emptyset\}$. If voting is simultaneous then the vote-history is empty for all committee members. We indicate by $\xi^{j} \in\{$ simultaneous, sequential $\}$ the voting procedure for question $j$.

Signals. For every voting question $j$, each committee member $i^{j}$ receives a private signal about the state. The signals are i.i.d. conditional on the state. The private signal $S_{i}^{j}$ has the following linear state-contingent densities (following Cipriani and Guarino $(2014))$ :

$$
\begin{aligned}
& f^{1}\left(s_{i}^{j} \mid \theta^{j}=1\right)=1+\tau\left(2 s_{i}^{j}-1\right) \\
& f^{0}\left(s_{i}^{j} \mid \theta^{j}=0\right)=1-\tau\left(2 s_{i}^{j}-1\right)
\end{aligned}
$$

where $\tau \in(0, \infty)$. (See Figure 1.)

The parameter $\tau$ is a measure of the level of strength in the experts' signals, where a larger $\tau$ means higher precision. In the case of the FDA's advisory boards, member $i^{j}$ 's signal realization can be thought of as a process whereby member $i^{j}$ considers the results and design of the clinical trials and draws on his/her personal experience, intuition, and analytical skills within a particular field (also allowing for randomness and misconceptions).

When $\tau \leq 1$ the support of the densities is $[0,1]$. For $\tau>1$, the support shrinks 
to $\left[\frac{\tau-1}{2 \tau}, \frac{\tau-1+2 \sqrt{\tau}}{2 \tau}\right]$ for $f^{1}$ and $\left[\frac{\tau+1-2 \sqrt{\tau}}{2 \tau}, \frac{\tau+1}{2 \tau}\right]$ for $f^{0} .^{8}$ The signals satisfy the monotone likelihood ratio property. For committee member $i^{j}$, the likelihood ratio after receiving signal $s_{i}^{j}, \frac{\left.P\left(\theta^{j}=1\right) \mid h_{i}^{j}, s_{i}^{j}\right)}{\left.P\left(\theta^{j}=0\right) \mid h_{i}^{j}, s_{i}^{j}\right)}=\frac{f^{1}\left(s_{i}^{j} \mid \theta^{j}=1\right)}{f^{0}\left(s_{i}^{j} \mid \theta^{j}=0\right)} \frac{\left.P\left(\theta^{j}=1\right) \mid h_{i}^{j}\right)}{\left.P\left(\theta^{j}=0\right) \mid h_{i}^{j}\right)}$, is higher than the likelihood ratio before receiving the signal if $s_{i}^{j}>\frac{1}{2}$ and lower if $s_{i}^{j}<\frac{1}{2}$. In this way, a signal larger than one half is affirmative news and a signal lower than one half is negative news regarding the yes/no question at hand. ${ }^{9}$

[Insert Figure 1 here.]

Types and payoffs. Committee members want their vote to match the state and may require a higher or lower standard of proof $(\pi)$ in order to vote yes. We define the payoffs for member $i^{j}$ as follows:

$$
\text { Payoff }= \begin{cases}0, & \text { if } v_{i}^{j}=\theta \\ -\pi, & \text { if } v_{i}^{j}=1 \text { and } \theta^{j}=0 \\ -(1-\pi), & \text { if } v_{i}^{j}=0 \text { and } \theta^{j}=1\end{cases}
$$

where $\pi \in(0,1)$.

Voters can be of two types depending on the information they use to infer the state: Herd types $(t=H)$ are Bayesian members who condition their vote on the common prior about the state, their private information, as well as on the history of votes of previous members along the sequence. In a variant of the model, we also consider herd types who follow a naïve updating rule (as in Eyster and Rabin, 2010). Expressive types $(t=E)$ are myopic voters who disregard the information contained in previous votes and only condition on the common prior and their private information. In effect, the expressive type always stays true to his/her own assessment based solely on the prior and the private signal. Instead of assuming that the expressive type (myopically) ignores

\footnotetext{
${ }^{8}$ The intervals ensure that the density functions integrate to one.

${ }^{9}$ As explained in Cipriani and Guarino (2014), when $\tau \geq 1$ there are some signal realizations, $s_{i}^{j}$, that are only possible when the state is 1 (or 0 ), which then reveal the true state with certainty to member $i^{j}$. In fact, when $\tau \geq 1$ signal realizations higher than or equal to $\frac{\tau+1}{2 \tau}$ are only possible when the state is 1 and signal realizations lower than or equal to $\frac{\tau-1}{2 \tau}$ are only possible when the state is 0 .
} 
any information from the vote history we could provide the expressive type with an additional negative payoff when voting against his/her own judgment that is based solely on the common prior and the private signal. This additional payoff would correspond to a psychological cost from not following one's own gut feeling (see e.g. Brennan and Pettit, 2000). These versions are equivalent in our setup and we have chosen the "myopic version" for simplicity. ${ }^{10}$

Types are distributed independently across voters and voting questions and the probability that a committee member is the herd type is $\lambda$. A member's type is private information. When $\pi>0.5(\pi<0.5)$ we say that the experts are cautious (incautious) and it requires relatively more (less) affirmative evidence to vote "yes" ("no"). The parameters $\lambda, \pi$ and $\tau$ are common knowledge. In the empirical analysis we consider heterogeneity in $\tau, \lambda$ and $\pi$ across committee members with differing observable characteristics.

The motivation behind the structure of payoffs is the assumption that experts want to answer the FDA's questions correctly and to the best of their abilities. ${ }^{11}$ Furthermore committing type 1 or type 2 voting errors may not weight the same, giving rise to a threshold of doubt that is different from one half.

We can formally characterize the voting behavior of member $i^{j}$ when he/she is the expressive type. Let $\bar{s}_{i, t=E}^{j}$ indicate the cut-off signal such that $P\left(\theta^{j}=1 \mid \bar{s}_{i, t=E}^{j}\right)=\pi{ }^{12}$ Using Bayes' rule and the law of total probability:

$$
P\left(\theta^{j}=1 \mid \bar{s}_{i, t=E}^{j}\right)=\pi \Longleftrightarrow \bar{s}_{i, t=E}^{j}=\frac{\mu_{0}^{j}-\pi}{2 \tau\left(2 \mu_{0}^{j} \pi-\pi-\mu_{0}^{j}\right)}+\frac{1}{2}
$$

\footnotetext{
${ }^{10}$ While anecdotal, discussions with experts who have previously served on an FDA Advisory Committee during the era of sequential voting indicate that some experts made a point of deciding on their vote before the voting starts, while others were open to adjusting their vote during the voting procedure. One expert stated that her vote was determined before voting (S. Caprio, personal communication, February 10, 2020). Another expert explained that most of the time his mind was made up before casting his vote, but after hearing the potentially novel perspectives earlier on in the voting sequence there would be a $10 \%$ chance that he would change his vote based on these discussions, however any change in vote was just as likely to move against the "herd" as with it (T. Carpenter, personal communication, February 12, 2020).

${ }^{11}$ Discussions with experts indicate that experts are motivated to partake in committee meetings to gain insight into the drug review process, learn how to critique an application and to "give back" to the government or "be a good citizen". Financial compensation is not an incentive to partake in meetings. With their vote, experts communicate what they believe is the correct answer to the question to the best of their abilities (S. Caprio, personal communication, February 10, 2020).

${ }^{12}$ Recall that the signals satisfy the monotone likelihood ratio property, see Duggan and Martinelli (2001) for how this translates into a voting rule characterized by a threshold crossing condition.
} 
The cutoff signal from equation (1) characterizes voting behavior of the expressive type: vote yes if $s_{i}^{j}>\bar{s}_{i, t=E}^{j}$ and vote no if $s_{i}^{j}<\bar{s}_{i, t=E}^{j} \cdot{ }^{13}$

The herd type uses the history of votes to update his/her beliefs about $\theta^{j}$. Let $\mu_{i}^{j} \equiv$ $P\left(\theta^{j}=1 \mid h_{i}^{j}\right)$ indicate member $i^{j}$ 's beliefs about the state after observing the preceding votes (not yet taking his/her own signal into account) and updating using Bayes' rule (or naïve updating). Optimal voting behavior for the herd type can be characterized by the cut-off signal, $\bar{s}_{i, t=H}^{j}$ :

$$
P\left(\theta^{j}=1 \mid \bar{s}_{i, t=H}^{j}, h_{i}^{j}\right)=\pi \Longleftrightarrow \bar{s}_{i, t=H}^{j}=\frac{\mu_{i}^{j}-\pi}{2 \tau\left(2 \mu_{i}^{j} \pi-\pi-\mu_{i}^{j}\right)}+\frac{1}{2}
$$

Member $i_{t=H}^{j}$ votes yes if $s_{i}^{j}>\bar{s}_{i, t=H}^{j}$ and no if $s_{i}^{j}<\bar{s}_{i, t=H}^{j} \cdot{ }^{14}$ Under simultaneous voting $\bar{s}_{i, t=E}^{j}=\bar{s}_{i, t=H}^{j}$

Note that increases in $\tau$ makes the value of the cut-off signal move towards one half (from below when $\mu>\pi$ and from above when $\mu<\pi$ ). Moreover, the cut-off signal becomes less sensitive to changes in $\mu$ and $\pi$ when $\tau$ increases. As illustrated in Figure 2 the cut-off is decreasing in $\mu$. In particular, the cut-off value is decreasing at an increasing (decreasing) rate when $\pi>0.5(\pi<0.5)$. In comparison to a committee member following the preponderance of evidence $(\pi=0.5)$, there is a larger range of signals for which an incautious expert will vote yes, and a smaller range of signals for which a cautious expert votes yes. This difference in the signal required to vote yes is most pronounced when the common prior is close to 0.5 .

[Insert Figure 2 here.]

\footnotetext{
${ }^{13}$ Note that the cut-off signal from (1) is outside its support when $\tau<1$ and $\mu_{0}^{j} \notin\left(\frac{1-\tau}{\frac{1}{\tau}+\frac{\tau}{\pi}-2 \tau}, \frac{\tau+1}{\frac{1}{\pi}-\frac{\tau}{\tau}+2 \tau}\right)$. If $\mu_{0}^{j} \leq \frac{1-\tau}{\frac{1}{\pi}+\frac{\tau}{\pi}-2 \tau}$ it is optimal for member $i_{t=E}^{j}$ to vote no for any signal realization and when $\mu_{0}^{j} \geq \frac{\tau+1}{\frac{1}{\pi}-\frac{\tau}{\pi}+2 \tau}$ it is optimal for member $i_{t=E}^{j}$ to vote yes for any signal realization.

${ }^{14}$ The cut-off signal from $(2)$ is outside its support when $\tau<1$ and $\mu_{i}^{j} \notin\left(\frac{1-\tau}{\frac{1}{\tau}+\frac{\tau}{\tau}-2 \tau}, \frac{\tau+1}{\frac{1}{\tau}-\frac{\tau}{\pi}+2 \tau}\right)$. When $\mu_{i}^{j} \leq \frac{1-\tau}{\frac{1}{\pi}+\frac{\tau}{\pi}-2 \tau}$ it is optimal for member $i_{t=H}^{j}$ to vote no for any signal realization and when $\mu_{i}^{j} \geq \frac{\tau+1}{\frac{1}{\pi}-\frac{\tau}{\pi}+2 \tau}$ it is optimal for member $i_{t=H}^{j}$ to vote yes for any signal realization.
} 


\section{$2.1 \quad$ Herd voting}

We refer to the notion of local herd voting whenever a herd type is swayed by the history of votes. ${ }^{15}$ That is, when the herd type, following the cutoff rule, votes yes (no), whereas had he/she ignored the vote-history and followed the cutoff rule in (1), like the expressive type, he/she would have voted no (yes). In addition, we term it local cascade voting if it is optimal for committee member $i_{t=H}^{j}$ to vote, say yes, for any possible private signal realization and, at the same time, had member $i_{t=H}^{j}$ ignored the vote-history he/she would have voted no after observing $s_{i, t=H}^{j}$. Cascade voting is only possible when $\tau<1$. The formal definitions are:

DEFINITION 1 (herd-voting): Provided that $\tau \geq 1$ or $\tau<1$ and $\mu_{i}^{j} \in\left(\frac{1-\tau}{\frac{1}{\pi}+\frac{\tau}{\pi}-2 \tau}, \frac{\tau+1}{\frac{1}{\pi}-\frac{\tau}{\pi}+2 \tau}\right)$, committee member $i_{t=H}^{j}$ engages in herd-yes-voting if $\bar{s}_{i, t=E}^{j}>s_{i, t=H}^{j}>\bar{s}_{i, t=H}^{j}$ and herdno-voting if $\bar{s}_{i, t=E}^{j}<s_{i, t=H}^{j}<\bar{s}_{i, t=H}^{j}$.

DEFINITION 2 (cascade-voting): Given $\tau<1$, committee member $i_{t=H}^{j}$ engages in cascade-yes-voting if $\mu_{i}^{j} \geq \frac{\tau+1}{\frac{1}{\pi}-\frac{\tau}{\pi}+2 \tau}$ and $s_{i, t=H}^{j}<\bar{s}_{i, t=E}^{j}$ and cascade-no-voting if $\mu_{i}^{j} \leq$ $\frac{1-\tau}{\frac{1}{\pi}+\frac{\tau}{\pi}-2 \tau}$ and $s_{i, t=H}^{j}>\bar{s}_{i, t=E}^{j}$.

Unless $\tau<1$ and $\mu_{0}^{j} \notin\left(\frac{1-\tau}{\frac{1}{\pi}+\frac{\tau}{\pi}-2 \tau}, \frac{\tau+1}{\frac{1}{\pi}-\frac{\tau}{\pi}+2 \tau}\right.$ ) or $\mu_{0}^{j}=\mu_{i}^{j}$ (which is the case for simultaneous voting and the first voter under sequential voting) there will always be some private signal realizations whereby member $i_{t=H}^{j}$ engages in herd- or cascade voting. ${ }^{16}$ Cascade voting is not possible when $\tau \geq 1$, as there will always be some possible private signal realization that shifts the beliefs across the herd type's threshold and thus herd types never ignore their signal when $\tau \geq 1$. Even if $\tau$ and $N$ are large the updated prior cannot hit 1 or 0 . When $\mu_{0}^{j}<\mu_{i}^{j}$ the probability that member $i_{t=H}^{j}$ engages in herd-yes-voting can be computed as the probability that $s_{i, t=H}^{j}$ lands in the interval $\left[\bar{s}_{i, t=H}^{j}, \bar{s}_{i, t=E}^{j}\right]$ (NB the

\footnotetext{
${ }^{15}$ This definition of herd voting is similar to herd-buying and herd-selling in Cipriani and Guarino (2014)

${ }^{16}$ Note that when $\tau<1$ and $\mu_{0}^{j} \notin\left(\frac{1-\tau}{\frac{1}{\tau}+\frac{\tau}{\tau}-2 \tau}, \frac{\tau+1}{\frac{1}{\tau}-\frac{\tau}{\tau}+2 \tau}\right)$ there is no private signal realization that can overcome the prior and expressive- and herd types always vote the same. In this case, learning is stuck from the beginning.
} 
linearity of the state contingent signals allow for analytical solutions). Similarly when $\mu_{0}^{j}>\mu_{i}^{j}$ and herd-no-voting is possible. Thus, a larger discrepancy between $\mu_{0}^{j}$ and $\mu_{i}^{j}$ implies that the probability of a herd vote increases. However, for $\tau<1$ and a sufficiently extreme $\mu_{i}^{j}$ the herd type will ignore his/her signal and cascade vote. This does not imply that all subsequent herd-types will cascade, as votes from expressive types may reverse the beliefs about $\theta^{j}$. Even for $\tau<1$ a positive measure of expressive types ensures that learning never ceases and is unbounded.

\subsection{The likelihood function}

The likelihood function under Bayesian updating. To estimate our voting model we have to specify its likelihood function. Recall that the state is independently drawn across the voting questions $j=1, \ldots, J$ and the private signals $\left\{s_{1}^{j}, \ldots, s_{N^{j}}^{j}\right\}$ are independent and identically distributed conditional on $\theta^{j}$. Therefore, the events $v^{j}=v_{1}^{j}, \ldots, v_{N^{j}}^{j}$ and $v^{k \neq j}=v_{1}^{k \neq j}, \ldots, v_{N^{k \neq j}}^{k \neq j}$ are independent and the likelihood of a sequence of votes over the set of voting questions can be written as

$$
P\left(\left\{v^{j}\right\}_{j=1}^{J} \mid \Phi\right)=\prod_{j=1}^{J} P\left(v^{j} \mid \Phi\right)
$$

Where $\Phi$ is the vector of parameters $\left\{\mu_{0}, \tau, \lambda, \pi, \xi\right\}$. To demonstrate how to derive $P\left(v^{j} \mid \Phi\right)$ we consider sequential voting and any voting sequence $v^{j}=v_{1}^{j}, \ldots, v_{N^{j}}^{j}$.

$$
\begin{array}{r}
P\left(v^{j} \mid \Phi\right)=\mu_{0}^{j} \prod_{i=1}^{N^{J}} P\left(v_{i}^{j}=1 \mid \Phi, h_{i}^{j}, \theta^{j}=1\right)^{v_{i}^{j}} P\left(v_{i}^{j}=0 \mid \Phi, h_{i}^{j}, \theta^{j}=1\right)^{1-v_{i}^{j}} \\
\quad+\left(1-\mu_{0}^{j}\right) \prod_{i=1}^{N^{J}} P\left(v_{i}^{j}=1 \mid \Phi, h_{i}^{j}, \theta^{j}=0\right)^{v_{i}^{j}} P\left(v_{i}^{j}=0 \mid \Phi, h_{i}^{j}, \theta^{j}=0\right)^{1-v_{i}^{j}}
\end{array}
$$

Conditional on the state and the voting history $h_{i}^{j}$, the individual votes are independent across the members. Thus, the vector of votes follows a mixture distribution, with mixing 
probability $\mu_{0}^{j}$. The state specific voting probabilities are calculated as follows: ${ }^{17}$

$$
\begin{aligned}
P_{1, i} \equiv P\left(v_{i}^{j}=1 \mid \Phi, h_{i}^{j}, \theta=1\right)= & \lambda P\left(s_{i}^{j}>\bar{s}_{i, t=H}^{j} \mid \Phi, h_{i}^{j}, \theta=1\right) \\
& +(1-\lambda) P\left(s_{i}^{j}>\bar{s}_{i, t=E}^{j} \mid \Phi, \theta=1\right) \\
P_{0, i} \equiv P\left(v_{i}^{j}=1 \mid \Phi, h_{i}^{j}, \theta=0\right)= & \lambda P\left(s_{i}^{j}>\bar{s}_{i, t=H}^{j} \mid \Phi, h_{i}^{j}, \theta=0\right) \\
& +(1-\lambda) P\left(s_{i}^{j}>\bar{s}_{i, t=E}^{j} \mid \Phi, \theta=0\right)
\end{aligned}
$$

To solve for $\bar{s}_{i, t=H}^{j}$ we need member $i$ 's updated probability that the state is good, given the history of votes. We do this recursively, whereby using Bayes rule

$$
\mu_{i}^{j} \equiv P\left(\theta^{j}=1 \mid h_{i}^{j}\right)=\frac{\mu_{i-1}^{j} P_{1, i-1}^{v_{i-1}}\left(1-P_{1, i-1}\right)^{1-v_{i-1}}}{\mu_{i-1}^{j} P_{1, i-1}^{v_{i-1}}\left(1-P_{1, i-1}\right)^{1-v_{i-1}}+\left(1-\mu_{i-1}^{j}\right) P_{0, i-1}^{v_{i-1}}\left(1-P_{0, i-1}\right)^{1-v_{i-1}}}
$$

for $i \geq 2$ and our base is $\mu_{1}^{j}=\mu_{0}^{j}$. If voting is simultaneous we can compute $P\left(v^{j} \mid \Phi\right)$ in the same manner, with the important difference that all the committee members vote with an empty vote-history.

The likelihood function under naïve updating. If herd types are "naïve", as in Eyster and Rabin (2010), they (incorrectly) believe that each previous person's action reflects solely that person's private information. In our model this translates into herd types believing that everyone before them is an expressive type. This assumption requires an adjustment to the way we calculate the updated prior. We denote the updated prior under the assumption of naïve updating as $\mu_{N, i}^{j}$.

$$
\mu_{N, i}^{j} \equiv P\left(\theta^{j}=1 \mid h_{i}^{j}\right)=\frac{\mu_{N, i-1}^{j} P_{N, 1, i-1}^{v_{i-1}}\left(1-P_{N, 1, i-1}\right)^{1-v_{i-1}}}{\mu_{N, i-1}^{j} P_{N, 1, i-1}^{v_{i}-1}\left(1-P_{N, 1, i-1}\right)^{1-v_{i-1}}+\left(1-\mu_{N, i-1}^{j}\right) P_{N, 0, i-1}^{v_{i}-1}\left(1-P_{N, 0, i-1}\right)^{1-v_{i-1}}}
$$

\footnotetext{
${ }^{17}$ By the monotone likelihood ratio property of the signals it is ensured that $P_{1, i} \geq P_{0, i}$ and we can identify the state-specific voting probabilities. Identification in this setting is proven in a number of papers dealing with identification of mixture models such as Allman, Matias, and Rhodes (2009).
} 
where,

$$
\begin{aligned}
& P_{N, 1, i} \equiv P\left(v_{i}^{j}=1 \mid \Phi, h_{i}^{j}, \theta=1\right)=P\left(s_{i}^{j}>\bar{s}_{i, t=E}^{j} \mid \Phi, \theta=1\right) \\
& P_{N, 0, i} \equiv P\left(v_{i}^{j}=1 \mid \Phi, h_{i}^{j}, \theta=0\right)=P\left(s_{i}^{j}>\bar{s}_{i, t=E}^{j} \mid \Phi, \theta=0\right)
\end{aligned}
$$

\section{Data}

\subsection{FDA Advisory Committees}

In the United States the producers of new drugs are required to win approval from the FDA in order to market their products. The review process gives the FDA the option to refer a matter of drug approval to one of its advisory committees. Around half of the drugs that the FDA reviews goes to a committee - typically those where the available data renders decision making particularly difficult or the drug or disease involved is controversial (Moffitt, 2010). Advisory committees are intended to provide the FDA with independent opinions and recommendations from outside experts. Although the expert committees provide recommendations to the FDA, the FDA makes the final decisions and usually obtains additional clinical data and has discussions internally and with the sponsor company after the committee meetings are held. ${ }^{18}$ At the beginning of a meeting the FDA and the sponsor company present data from clinical trials and results regarding the risks and benefits of the drug or product under consideration. After the presentations the committee members deliberate and usually, after lengthy discussions, vote on one or more questions put forth by the FDA. These questions are generally scientific in nature and can involve a range of subjects, including the assessment of a drug or biological product's efficacy, safety, or overall approvability.

There are currently 18 different advisory committees under the Center for Drug Evaluation and Research. The committees are specialized on a particular disease or topic e.g.

\footnotetext{
${ }^{18}$ As explained by the clinical FDA team leader at the meeting of the approval of Olodaterol: "Before I close, I just wanted to mention the legal framework that gives the FDA the ability to hold advisory committees to ask for scientific advice and recommendations from experts in the field. As I noted previously, the FDA takes very seriously the advice of the committee. However, the Commissioner has sole discretion on actions taken with regard to drug approval, especially since there may be other issues, such as manufacturing, not discussed at the meeting, that impact approval decisions."
} 
the Cardiovascular and Renal Drugs Advisory Committee or the Oncologic Drugs Advisory Committee. Each committee typically meets 1 to 4 times per year at the request of the FDA. On average a committee comprises around a dozen members. Each committee has a chair, who leads the meetings, several regular scientific members (serving 4-year terms), plus a qualified consumer and sometimes a patient representative. ${ }^{19}$ Additional experts are usually added as temporary voting members. Like regular members, the invited temporary members have recognized expertise in the relevant field. ${ }^{20}$ Temporary members can be invited outside experts, members of the center's consultancy pool, or members of other advisory committees. Before each meeting all the committee members receive briefing material for preparation.

Following the Draft Guidance for FDA Advisory Committees of 2007 the voting procedure changed from sequential to simultaneous (electronic) voting. ${ }^{21}$ Under sequential voting the polling starts at one end of the committee table, at the chair's discretion, and continues in a stepwise fashion according to the seating plan of the meeting. The seating plan is jointly decided by the committee's executive secretary and the chair. In Appendix A we provide evidence that, based on observable member characteristics, there are no clear patterns in the way that the committee members are seated (except for the chairperson). When a meeting has several voting questions, which is often the case, the chair usually alternates so that voting starts at each end of the committee table at every other voting question (on few occasions also starting from the middle and going clockwise or counter-clockwise around the table). The chair also votes and is seated in a central position. Often members are allowed to accompany their votes with comments, motivation, or provisos. Under simultaneous voting the members place their votes with electronic voting pads and after the votes have been locked in they sequentially go on the record and state what they voted and give comments. The order of announcements follows the

\footnotetext{
${ }^{19}$ As stated by the FDA, the role of the consumer representative is to represent the consumer perspective and serve as a liaison between the committee and interested consumers and consumer organizations. The consumer representatives are usually experts in the field like the regular committee members. Patient representatives have experience with the disease either as a patient or primary caregiver.

${ }^{20}$ Guidance for Industry, Advisory Committees: Implementing Section 120 of the Food and Drug Administration Modernization Act of 1997.

${ }^{21}$ In the transition from sequential to electronic voting some committee meetings used voting by a show of hands. We exclude these meetings from our analysis.
} 
seating plan of the meeting and the chair decides at which end of the table to begin. As with sequential voting, the chair usually alternates so that the announcements starts at each end of the committee table at every other voting question.

Around the same time the voting procedure changed, the FDA Amendments Act of 2007 was passed by Congress. Notably, the law established a limit on the number of committee members with financial conflicts. ${ }^{22}$ Under USC Section 208, the FDA has authority to grant waivers to committee members who have potential financial conflicts when it is determined that the need for a particular individual's services outweighs his or her potential financial conflict of interest. ${ }^{23}$ One concern is whether the decline in conflict of interest (COI) waivers occurring around the time of the shift in voting procedure could have caused the changes in voting patterns that we see in the data. In our analysis we control for COI waivers and we are able to rule out that this change is driving our results.

\subsection{Data collection and variables}

Our data source is the full set of meeting transcripts that can be downloaded via www.fda.gov. The public records start in 1996 and we have data until June 2014. We consider committee meetings with one or more binary voting questions on the agenda and where the overall topic concerns approval of a drug or biological product. For sequential voting, this gives us 138 committee meetings and 375 binary voting questions with the full sequence of votes and for simultaneous voting it is 189 committee meetings and 438 voting questions. In total the data consists of 10,466 yes or no votes. ${ }^{24}$ A "yes" vote is always associated with a favorable assessment of the relevant drug or biological product. This means that on a few occasions (negated questions) we reverse the votes. On average a committee comprises of 13 members, with a minimum of 5 members and a maximum of 28 members.

For each committee meeting, we indicate whether voting is simultaneous or sequential,

\footnotetext{
${ }^{22}$ The law also extended the authority to levy fees on companies applying for drug approvals, expanded clinical trial guidelines for pediatric drugs and enhanced the authorities to require post-approval studies.

${ }^{23}$ Potential financial conflicts include investments, consulting, expert witness testimony, grants, patents and royalties, and primary employment in the sponsor company or its competitors.

${ }^{24}$ The voting members also have the option to abstain, although they rarely do so. In our data, 1.2 percent of the sequential votes are abstentions and 2.7 percent of the simultaneous votes are abstentions. For simplicity we ignore abstentions in our analysis (the individual abstentions drop out as if they had not been placed).
} 
the name of the advisory committee, type of application, and proposed trade name. ${ }^{25}$ Our data covers 15 different topical committees. Applications can be a New Drug Application, a Biologic License Application, a supplemental New Drug Application, or a supplemental Biologic License Application. ${ }^{26}$ Drug applications can be under "priority review"; a mechanism which seeks to expedite the review process for drugs that are expected to have a large impact on the treatment of a disease. Information on which applications are under priority review is obtained from the Drugs@FDA database.

We record the wording of the voting question and classify it depending on whether the question is about efficacy, safety, approval, or other (e.g. questions about methodology, dose, or labeling). We also report a score on the FDA reviewer(s) assessment of efficacy, safety, and approval. The FDA reviewer score is based on the FDA presentations and introductory remarks. Before each committee meeting the FDA's review team analyses the efficacy and safety studies in question and prepares presentations to be held in front of the committee. These presentations take place before the voting stage and the reviewers are not members of the committee and do not vote. The FDA reviewer score on efficacy $(1,0,-1)$ reflects the review team's conclusions regarding efficacy of the proposed drug or biological product. This revolves around the primary endpoints of the efficacy studies. ${ }^{27}$ If the FDA reviewer(s) state that all the primary endpoints were met (usually with respect to p-values less than 0.05) in all the efficacy studies we code the efficacy score as 1 . If the efficacy results are mixed or the FDA reviewer has major methodology concerns we code the efficacy score as 0 . If the FDA reviewer concludes that the drug or product has no effect we code the efficacy score as -1 .

The FDA reviewer score on safety $(1,0,-1)$ reflects the review team's conclusions regarding safety issues and adverse events. If the reviewer concludes that the safety profile is not worse than already approved products, or if the reviewer states that the

\footnotetext{
${ }^{25}$ In some cases, multiple drugs or products are considered on the same day and meetings are then split between morning and afternoon sessions.

${ }^{26}$ Companies are allowed to make changes to drugs and biological products or their labels after they have been approved. To change a label, market a new dosage or strength, or change the way the treatment is manufacturing, a company must submit a supplemental application.

${ }^{27}$ These studies are often placebo controlled trials, but can also be non-inferiority or superiority studies with respect to an already approved comparator.
} 
safety studies reveal no significant safety concerns, we record a score of +1 . On the other hand, if the FDA reviewer expresses serious safety concerns, also with respect to what is the standard for the relevant indication, we code the safety score as -1 . If neither explicit positive or negative conclusions are drawn from the safety review we code the safety score as 0 . Finally, the approval score simply adds the efficacy score to the safety score. Where the total score is 1 or higher, the FDA reviewer score for approval questions will be 1 , similarly when it is -1 or lower, the score will be -1 . In cases where there is no FDA reviewer assessment, we assign a score of $0 .^{28}$ Table 1 indicates the frequency of voting questions in each group.

\section{[Insert Table 1 here.]}

At the voting question level we record the individual votes. For meetings with simultaneous voting, we order the votes in the way that the committee members announce them as they go on the record after the votes have been locked in. For sequential voting, the votes are entered according the order in which they are cast. ${ }^{29}$ For each vote, we register the name of the voter, gender, educational background, whether he/she was granted a COI waiver for the given committee meeting, and whether the voter is a consumer representative, patient representative, regular or temporary member. All this information, except for gender, appears in the meeting transcripts or the summary minutes. In total, we observe the votes made by 1,378 unique voters. $12 \%$ of these voters (which account for $25 \%$ of votes) are present under both voting procedures. Table 2 indicates the frequency of voter characteristics, split by voting regime. A clear difference in committee composition after 2007 is the reduction in the number of members with a conflict of interest owing to the FDA Amendments Act. Another difference is the increased use of temporary committee members, as opposed to regular members, under simultaneous voting.

\footnotetext{
${ }^{28}$ Questions that are classified as 'other' receive a score of 0 . Meetings at the Cardiovascular and Renal Drugs Advisory Committee do not use FDA presentations until the end of 2005. For these meetings we insert reviewer scores of 0 .

${ }^{29}$ Under sequential voting, we have 20 voting questions with low data quality in the sense that the voting order was interrupted during voting (11), the voting question was modified after the first vote was given (5), or members did not precisely specify their vote (4). In the latter case, we include a yes or no vote depending on whether the member expressed himself/herself positively or negatively on the voting question. These voting questions are all included in our empirical analysis. None of our results or estimates significantly change depending on whether we include these observations or not.
} 
[Insert Table 2 here.]

\section{Descriptive analysis}

In this section, we construct descriptive statistics and use reduced-form techniques to investigate changes in vote outcomes and voting behavior following the switch to simultaneous voting. Our findings are consistent with herd behavior: The main insights are that the probability of a unanimous vote outcome and the probability of a committee member voting the same as the person seated before him/her are significantly higher under sequential voting. We also find significant differences in voting behavior across committee members with differing observable characteristics. This further warrants the estimation of our model which allows for sequential learning and heterogeneity in the behavior of committee members.

\subsection{Vote outcomes}

To obtain precursory insights into voting outcomes under sequential and simultaneous voting, we construct the following variables at the voting-question level; 1) an indicator variable that takes the value 1 if the outcome of the vote is unanimous, 2) the size of the majority (as a percentage) and 3) the percentage of yes votes. Descriptive statistics for these variables are presented in Table 3 . Under sequential voting $48 \%$ of vote outcomes are unanimous, this figure is $29 \%$ under simultaneous voting. Figure 3 shows the distribution of the percentage of yes votes for a given voting question. Clearly, there appears to be more agreement in votes under the sequential procedure.

[Insert Table 3 here.]

[Insert Figure 3 here.]

\subsection{Voting behavior}

In this subsection we run several regressions that model voting behavior at the individual level. The aim of this analysis is to convince the reader that there is a change in voting 
behavior following the switch to simultaneous voting, and that this change is in line with herd behavior under sequential voting. Furthermore, we use regression analysis to explore differences in voting behavior across different types of committee members.

In our analysis we focus on three outcome variables; 1) an indicator variable taking the value 1 if member $i$ 's vote matches the preceding vote: $\left.I\left(v_{i}^{j}=v_{i-1}^{j}\right)^{30}, 2\right)$ an indicator variable taking the value 1 if a member votes in line with the majority up until that point: I(WithMajority), and 3) an indicator variable taking the value 1 if a member votes "yes": $I\left(v_{i}^{j}=y e s\right)$. The first two measures aim to (crudely) reflect how individuals are influenced by previous votes. The regression specifications take the following form:

$$
\operatorname{Pr}\left[I_{i j}=1\right]=\gamma_{0}+\gamma_{1} \text { Sequential }_{j}+X_{i j} \delta+\epsilon_{i j}
$$

where $I_{i j}$ is one of three binary dependent variables outlined above, Sequential ${ }_{j}$ is an indicator variable for a sequential voting procedure and $X_{i j}$ is a vector of individual-level and question-level covariates.

At the question-level we control for committee size, FDA reviewer score, whether or not the drug is under priority review, if the application pertains to a biological product, if the application is a supplementary application, and the share of members in the committee with a conflict of interest waiver (as a percentage). We include fixed effects for the 15 topical committee categories and four question types (efficacy, risk vs. benefit, safety, other). At the individual-level we control for the member's position in the voting order ("seat"), voter type (i.e. temporary, regular, consumer representative and patient representative), level of education, gender and whether or not the committee member has a conflict of interest waiver. In order to provide an initial indication of heterogeneity in behavior across different types of committee members, we estimate specifications with interaction terms between individual characteristics and sequential voting.

Table 4 provides summary statistics for the three outcome variables and the noncategorical explanatory variables. There is substantial variation in the share of members

\footnotetext{
${ }^{30}$ For simultaneous and sequential voting the order we use follows the order in which votes are announced.
} 
with a COI waiver, both under sequential and simultaneous voting, which we use to separate the effect of a change in voting procedure from the effect of new regulations introduced around the same time which limited the number of members with a COI waiver. ${ }^{31}$

\section{[Insert Table 4 here.]}

Table 5 presents the regression results using ordinary least squares. ${ }^{32}$ Note that we exclude the first vote when using $I\left(v_{i}^{j}=v_{i-1}^{j}\right)$ and $I$ (WithMajority) as the dependent variable. We also exclude votes that follow a 50/50 outcome from regressions where $I$ (WithMajority) is the dependent variable. Controlling for observable vote and voter characteristics, on average, the probability that a member's vote is the same as the previous vote is 6.3 percentage points higher under sequential voting (column 1). Further, a committee member is almost 5 percentage points more likely to vote with the present majority under sequential voting (column 3). The probability to vote yes is higher for sequential voting (column 5). These findings are consistent with earlier votes influencing later votes under sequential voting.

A number of additional results are worth pointing out. We find that regular members are significantly less likely to vote with the present majority under sequential voting. Patient representatives are also less likely to vote with present majority under sequential voting (column 4). Furthermore, we find that both variables which control for the change in COI waivers (Share COI and COI waiver) do not significantly affect the probability that a member's vote matches the preceding vote or the probability of voting in line with the present majority. The positive sign on the interaction between Seat and Sequential in columns 2 and 4 provides some (weak) evidence that a committee member is more likely to be influenced by previous votes the later on in the sequence they vote.

In columns 5 and 6 we report which variables are correlated with a member's probability to vote "yes". An FDA reviewer score of -1 is negatively and significantly correlated with

\footnotetext{
${ }^{31}$ The share of members with a COI waiver under sequential voting ranges from a minimum of 0 to a maximum of 1 , with a standard deviation of 0.19 and a mean of 0.23 . The share of members with a $\mathrm{COI}$ waiver under sequential voting ranges from a minimum of 0 to a maximum of 0.3 , with a standard deviation of 0.04 and a mean of 0.013 .

${ }^{32}$ Our results are robust to probit and logit specifications.
} 
voting yes, whereas a score of 1 is positively and significantly correlated with voting yes. Priority drugs are also more likely to receive yes votes on average, as well as biological medications. ${ }^{33}$ As might be expected, we find that consumer representatives are less likely to vote in favor of a drug all else constant, whereas patient representatives are more likely to vote "yes".

The share of members in the committee with a conflict of interest waiver does not have a significant impact on the probability to vote in favor of the drug. There is some (weak) evidence that members with a conflict of interest may be more likely to vote in favor of a drug under simultaneous voting, but are relatively less likely to do so under sequential voting. It is not surprising that we do not find a strong effect of COI waivers on voting behavior. Previous studies using voting data from the FDA's advisory committees have produced mixed results concerning the connection between voting and industry ties. ${ }^{34}$

Overall, a descriptive analysis of the data suggests that there is a change in voting behavior following the switch to simultaneous voting and provides evidence consistent with earlier votes influencing later votes under sequential voting. However, we cannot rule out the possibility that voting outcomes may be driven by more extreme priors for the voting questions under the sequential procedure, which would lead to more agreement (regardless of the voting procedure). This is something that our reduced form model cannot directly control for. Moreover, even if we believe that, on average, the priors are similar for the sequential and simultaneous voting questions, a reduced-form model cannot speak to the mechanism that causes more agreement in the case of sequential voting or quantify the extent of "herd votes". A structural approach is invaluable in this situation to explicitly incorporate the unobserved prior for each voting question, experts' private

\footnotetext{
${ }^{33}$ Later, we will use these features of vote questions to characterize the prior in our structural model.

${ }^{34}$ Lurie and Zieve (2006) find a weak positive relationship between members' votes for approval and financial ties. Ackerley et al. (2009) expand the data-set used in Lurie and Zieve (2006) and show a tendency for committee members to vote against their financial interests. Pham-Kanter (2014) finds that individuals with financial interests solely in the sponsoring firm are more likely to vote in favor of the sponsor than members with no financial ties. Cooper and Golec (2017) find that conflicts of interests are not significantly related to votes in FDA committees. Using a structural model, Camara and Kyle (2016) estimate each member's skill and bias associated with financial ties to a drug's sponsor or its competitors. Their results suggest that members with financial ties are more likely to vote in favor of both "good" and "bad" drugs. However, members with financial ties also have somewhat higher estimated ability, and hence are more favorable towards good drugs. Notably, these studies do not distinguish between sequential and simultaneous voting.
} 
information and differences in the cautiousness of experts in order to provide estimates that have a clear interpretation in the context of a model of herd behavior. Ultimately, using our model and the estimated parameters, we can also say something about which voting procedure leads to more efficient information aggregation.

\author{
[Insert Table 5 here.]
}

\title{
5 Estimation and identification
}

In this section, we describe the specification of the prior and the estimation of our model. We then provide some intuition on which variation in the data allows us to identify the parameters of the model.

To make the model tractable, we place a parametric restriction on the prior. ${ }^{35} \mathrm{We}$ allow the prior $\mu_{0}^{j}$, the common belief that the correct answer to the voting question is yes, to depend parametrically on characteristics of the voting question captured by $X_{j}$ (e.g. FDA reviewer score) via the following logit formulation:

$$
\mu_{0}^{j}\left(X_{j} ; \beta\right)=\frac{\exp \left(X_{j}^{\prime} \beta\right)}{1+\exp \left(X_{j}^{\prime} \beta\right)} \in(0,1)
$$

This specification implies that there are certain observable vote characteristics that have an effect on the probability of the state being "yes" or "no". The state for each voting question $j$ is determined by these characteristics and a question-specific unobserved shock term drawn from a standard logistic distribution. In Appendix B we elaborate on how this specification can accommodate correlation in the true state for voting questions that are part of the same meeting.

To incorporate heterogeneity in herd behavior, caution and expertise we specify $\lambda$, $\pi$ and $\tau$ as a function of categorical voter characteristics including category of committee member (Regular, Temporary, Consumer Representative or Patient Representative),

\footnotetext{
${ }^{35}$ This is in line with previous literature e.g. Iaryczower and Shum (2012) and Camara and Dupius (2014)
} 
gender, whether or not the committee member has a $\mathrm{PhD}$ and whether or not the member has a conflict of interest. Specifically,

$$
\begin{gathered}
\lambda_{i}=\gamma_{\text {reg. }}+\gamma_{\text {temp. }}+\gamma_{\text {cons. }}+\gamma_{\text {pat. }}+\gamma_{\text {phd }}+\gamma_{C O I}+\gamma_{\text {male }} \\
\pi_{i}=\alpha_{\text {reg. }}+\alpha_{\text {temp. }}+\alpha_{\text {cons. }}+\alpha_{\text {pat. }}+\alpha_{\text {phd }}+\alpha_{C O I}+\alpha_{\text {male }} \\
\tau_{i}=\eta_{\text {reg. }}+\eta_{\text {temp. }}+\eta_{\text {cons. }}+\eta_{\text {pat. }}+\eta_{\text {phd }}+\eta_{C O I}+\eta_{\text {male }}
\end{gathered}
$$

Note that this specification defines four different intercepts for regular members, temporary members, patient and consumer representatives which can shift depending on gender, education and COI status. The parameters to be estimated are the vectors $\beta, \gamma, \alpha$ and $\eta$. To recover the parameter estimates, we maximize the likelihood function (3) directly using the full dataset of 10,466 individual votes. To find the parameters that minimize the negative log-likelihood function, we used both the quasi-Newton algorithm for unconstrained optimization and the Nelder-Mead simplex direct search algorithm. ${ }^{36}$ Standard errors are calculated by taking the square root of the diagonal elements of the inverse estimated Hessian of the likelihood function at the solution.

Regarding the model's identification, the degree of agreement in votes, the proportion of yes votes, the exact order of votes under sequential voting, and differences in how certain voters behave across questions are important. The prior, $\mu_{0}$, is identified by the proportion of yes votes at the vote question level. All experts tend to receive higher private signals when the state is "yes" and thereby a high prior will induce many yes votes. The level of cautiousness, $\pi$, is identified by variation in how many "yes" vs. "no" votes are cast across questions with different priors. A voter's $\pi$ follows them across questions with different priors. Intuitively, if a committee member (or group of committee members) is particularly cautious there will be less variation in their votes and they will vote "no" more often.

\footnotetext{
${ }^{36}$ Both methods converge to the same parameter estimates. We do not need to impose constraints on our parameters to obtain reasonable estimates. Results are robust to different starting values. We conducted a Monte Carlo exercise using a simulated dataset and verified that our procedure yields reasonably precise, unbiased estimates of the parameters of the model.
} 
The identification of $\tau$ is characterized by the degree of agreement in votes. An increase in $\tau$ is distinguishable from an increase in $\mu_{0}$, or a decrease in $\pi$, as the increase in $\tau$ may cause a higher concentration of both yes and no votes across multiple voting questions. At the individual level, a committee member with high expertise will be more likely to receive a signal that squares with the true state. Thus, members whose votes are typically in line with the majority, particularly under simultaneous voting, will be estimated as having a high expertise. The probability that a committee member is a herd type, $\lambda$, is identified by the sequence of votes and differences in how voters with certain characteristics react to the history of votes that they observe. Given $\mu_{0}, \pi$, and $\tau$ we can identify how likely it is that a voter is a herd type based on how they vote in response to previous voters. Intuitively, if we see a long sequence of yes votes, and thereafter a voter who votes no, this voter is more likely to be an expressive type.

While in theory, all parameters can be identified on the basis of sequential data alone, in practice, with a limited sample of voting questions under sequential voting and a limited number of committee members voting on each question, access to simultaneous data is crucial. Intuitively, both an increase in the precision of information and the share of herd types will create more agreement in votes, hence without access to simultaneous data identification of $\lambda$ hinges on the exact order of votes under non-unanimous outcomes. Simultaneous data is used to get a grip on $\tau$ (as well as $\mu_{0}$ and $\pi$ ) when there are no herd effects at play, which allows us to better separate the effect of these parameters from $\lambda .{ }^{37}$ Effectively, the results are similar to what would be obtained if we applied a two-step procedure whereby first simultaneous data is used to estimate $\tau, \pi$ and the determinants of the common prior, and then plugging these estimates into the model, sequential data is used to recover $\lambda$.

\footnotetext{
${ }^{37}$ This is confirmed by simulations where, with a limited number of voting questions, the accuracy of all parameter estimates is improved by using both simulated sequential and simultaneous data. Increasing committee size (the length of the sequence) also improves the estimates the parameters.
} 


\section{$6 \quad$ Estimation results}

In this section, we present our results for the voting model introduced in Section 2. We first present the estimates of the model parameters and then discuss the frequency of herd voting.

\subsection{Estimates}

Table 6 presents the estimates and the standard deviations for the parameters of the model. In the baseline model we do not include voter characteristics. We find that on average the probability that any given committee member is a herd type is close to one half (48\% for Bayesian version and $52 \%$ for naïve version). Put differently, on average half of committee members take into consideration the vote history when placing their vote under sequential voting. We should bear in mind that this does not mean that half of the committee members actually herd, that is, change their vote from what it would have been if ignoring the vote history. Herd types will only change their vote if the information inferred from the previous votes is sufficiently strong and opposite to their private information. It's not hard to find examples from the FDA transcripts where panelists are open about paying attention to the previous votes, without necessarily being swayed by them. ${ }^{38}$ We discuss our approach to quantifying herd votes in the following subsection.

We estimate the model allowing for heterogeneity across voters with different characteristics. We present the estimates for both the model which assumes standard Bayesian updating and the model which assumes naïve updating. The results are qualitatively similar, and hence we will focus our discussion on the model which assumes herd types are fully Bayesian.

The average proportion of herd types masks differences in $\lambda$ across voters with certain characteristics. The results indicate that temporary committee members are the most susceptible to herd behavior. Regular committee members and patients representatives

\footnotetext{
${ }^{38}$ For example, voting after one "yes" and four "no" votes it's Dr. Martino's turn: "Having struggled and heard all of you struggles, my answer is going to be no." From the meeting of the Oncologic Drugs Advisory Committee in March 2006 on the drug Gemzar.
} 
are less likely to be herd types. Members with a conflict of interest are more likely to be herd types. Finally, the results suggest that gender and whether or not an expert has a $\mathrm{PhD}$ has little impact on $\lambda$.

The low proportion of herd types among regular members compared to temporary members could be due to the fact that these members regularly participate in advisory meetings. This process would make their self-esteem and esteem as expert panelists fairly settled and potentially turn some regular "herd" members into expressive voters (see See Brennan and Pettit (2000) on the economics of esteem). Another explanation may be career concerns which are typically thought to be higher for less experienced members (see Hansen, McMahon, and Prat, 2018). Scharfstein and Stein (1990) show that agents with career concerns unsure of their expertise tend to herd on the same action, thereby avoiding being the only one to take an incorrect decision. Hong, Kubik, Solomon (2000) compare the behavior of inexperienced and experienced equity analysts and find that inexperienced analysts deviate less from consensus forecasts. They interpret this finding as being consistent with career-concern-motivated herding theories. With respect to social conformity, ${ }^{39}$ some experiments demonstrate that subjects are more likely to conform when grouped with strangers as opposed to friends (McKelvey and Kerr, 1988). In Appendix D we expand on our finding in Section 4.2 that regular members are less likely to vote with the present majority under sequential voting. We find that members who are attending a meeting for the first time are significantly more likely to vote with the majority under sequential voting. We are also able to rule out that a committee member's age is driving the result. This lends support to the conjecture that more frequent attendance of meetings can reduce the extent to which committee members are influenced by previous votes.

Our results indicate that gender does not impact the likelihood to be influenced by previous votes in the context of FDA Advisory Committees. This result is in contrast to

\footnotetext{
${ }^{39}$ In a social conformity framework, individuals are influenced by observing others' actions, not because of information revealed about an underlying state, but due to social dynamics, see Asch (1951). For discussions on the distinction between informational and social influence see Deutsch and Gerard (1955), Shiller (1995), and Bernheim and Exley (2015). In a field experiment conducted with a financial brokerage, Bursztyn et al. (2014) implement a novel design to separately identify these two channels of influence.
} 
previous findings from the social conformity literature. The results are mixed, however, Eagly and Carli (1981) performed a meta-analysis of 148 studies of influenceability and find that women are more persuadable and more conforming than men in group pressure situations that involve surveillance.

On average, we find that committee members are cautious and would prefer to incorrectly vote to reject a good drug than incorrectly vote to approve a bad drug. On average, members vote yes if they believe that the probability that the true state is "yes", given all information, is at least $58 \%$. We also find heterogeneity in the cautiousness of members. Consumer representatives are the most cautious as one might expect. On the other hand, patient representatives vote yes if the probability that the state is 1 is greater than $49 \%$. Unlike with the tendency to herd, the standard of proof required to vote in favor of a drug does not differ between temporary and regular committee members.

On average the precision of information for the FDA advisory committees is quite high $(\tau=1.26)$. This implies that the probability that a member gets an incorrect signal (i.e. a signal $<0.5$ when the state is 1 , or a signal $>0.5$ when the state is 0 ) is $20 \%$. Precision of information varies across committee members. Regular members have the most accurate private information whereas the signals of consumer and patient representatives are less likely to align with the true state.

We use information on the FDA reviewer score, whether the medication is a drug or biological product and whether the drug is under priority review to characterize the prior. The inclusion of these characteristics is motivated by which variables are significant in the reduced-form analysis. We find that our estimates are robust to the inclusion of more vote characteristics in the specification of the prior, e.g. inclusion of voting question type. We select this specification as it is parsimonious, while at same time providing a good sense of the range of $\mu_{0}$. In Appendix $\mathrm{C}$ results are presented for a model where we estimate a common prior for each committee meeting.

Estimates of the average common prior $\mu_{0}$ for categories of voting questions can be computed using $\beta$. For example, the average prior for voting questions relating to a drug under priority review with an FDA reviewer score of 1 can be computed as $\frac{\exp (1.67)}{1+\exp (1.67)}=$ 
0.84. Estimated average priors range from 0.44 to 0.84 .

$$
\text { [Insert Table } 6 \text { here.] }
$$

\subsection{Herd votes}

We now investigate the frequency of actual herd votes. Using our structural model and the estimated parameters we are able to construct a simulated dataset of votes under sequential and simultaneous voting. By comparing an individual's simulated vote under sequential and simultaneous voting we can directly observe which votes are herd votes.

We simulate a dataset of 1,000 vote questions which are voted on by a committee of 13 members (the average committee size) under both a sequential and simultaneous procedure. We use parameter values in line with our baseline estimates and repeat the procedure for three different values of the common prior; 0.5, 0.65 and $0.8 .^{40}$ Specifically, the procedure is as follows:

1. For each voting question draw an error term $\epsilon_{j}$ from the standard logistic distribution

2. Assign each voting question a state as follows: $\theta^{j}=1$ if $y_{j}^{*}>0$ and 0 otherwise, where $y_{j}^{*}=\beta+\epsilon_{j}$

3. Given $\theta^{j}$ and $\tau$, draw private signals for each voter, for each voting question

4. With probability $\lambda$ assign each voter to be a herd type

5. Given the assigned signals, $\mu_{0}, \tau$ and $\pi$ simulate voting under the simultaneous voting rule

6. Given the assigned signals, $\mu_{0}, \tau, \pi$, types and $\lambda$ simulate voting under the sequential voting rule

Thus, we have the same voters voting on the same voting question, once under simultaneous rule, and once under the sequential rule. If an individual votes differently under sequential voting, this is counted as a herd vote. We also compare the proportion of unanimous outcomes and the average size of the majority across the simulated datasets.

\footnotetext{
${ }^{40}$ The corresponding $\beta$ 's are $0,0.62$ and 1.39 .
} 
Table 7 presents key statistics calculated using the simulated data based on the Bayesian model. For a balanced prior, we find that $18.4 \%$ of herd types actually herd and thus $8.9 \%$ of all sequential votes are "herd votes". Across all three common priors, the proportion of herd votes is fairly stable at around $8.5 \%$. In each case the proportion of unanimous vote outcomes increases under sequential voting. The number of unanimous outcomes also increases as the common prior moves away from 0.5 and there is less uncertainty. With a prior of 0.8 , we find that $42.6 \%$ of vote outcome are unanimous under sequential voting, in comparison to $28.5 \%$ under simultaneous voting. Thus, voting data simulated according to our model is able to re-produce patterns similar to those appearing in the real data. ${ }^{41}$

Table 8 presents the same statistics for the case of naïve updating. Here, we find that roughly $9 \%$ of all sequential votes are herd votes and that unanimous outcomes occur more frequently. This is in part driven by a higher estimate of $\tau$ in the naïve model, which explains why the share of unanimous outcomes is also higher under simultaneous voting. In general, the patterns are similar to those observed under the assumption of Bayesian updating.

[Insert Table 7 here.]

[Insert Table 8 here.]

\section{Information aggregation}

In this section, we consider information aggregation through voting and how a switch to simultaneous voting affects the quality of the committee's overall assessment. We do this by calculating the probability that a committee of a given size makes the correct assessment about a medication under each voting procedure.

We define the committee's overall assessment as being favorable when the updated beliefs about the state being "yes" after everyone has voted is greater than one half.

\footnotetext{
${ }^{41}$ Although not directly comparable to the simulated dataset, recall that in the actual data, $47.7 \%$ of vote outcomes under sequential voting are unanimous and $28.8 \%$ under simultaneous voting.
} 
Beliefs about the state being "yes" after everyone has voted are computed in the same way that committee members update beliefs about the state (taking all the parameter values of the model into consideration). We consider both Bayesian and naïve updating.

Let $A^{j} \in\{0,1\}$ represent the committee's overall assessment for voting question $j$ where $A^{j}=1$ represents a favorable assessment of the drug. For each committee size $N$ we can calculate the probability that the assessment is correct (i.e. a favorable assessment of a good drug or a negative assessment of a bad drug) by calculating the number of instances where $A^{j}=\theta^{j}$ across all possible voting profiles and weighting appropriately by the probability of the state and the voting profile conditional on the state.

Let $v_{N}^{j}$ be a specific sequence of votes with $N$ voters. The set $V^{j}$ comprises of all possible voting sequences with $N$ voters. We denote the updated beliefs about the state after $N$ experts have voted by $\mu_{N+1}^{j}\left(v_{N}^{j}\right) \equiv P\left(\theta^{j}=1 \mid v_{N}^{j}\right)$. We assume $A^{j}\left(v_{N}^{j}\right)=1 \Longleftrightarrow$ $\mu_{N+1}^{j}\left(v_{N}^{j}\right)>0.5$. Let $I\left(\mu_{N+1}^{j}\left(v_{N}^{j}\right)>0.5\right)$ be an indicator variable that takes on the value one if $\mu_{N+1}^{j}\left(v_{N}^{j}\right)>0.5$. The probability that the committee's overall assessment is correct can be computed as follows:

$$
\begin{aligned}
\operatorname{Pr}\left(A^{j}\left(v_{N}^{j}\right)=\theta^{j}\right)=\mu_{0}^{j} \sum_{v^{j} \in V^{j}} & \operatorname{Pr}\left(v_{N}^{j} \mid \Phi, \theta=1\right) \times I\left(\mu_{N+1}^{j}\left(v_{N}^{j}\right)>0.5\right) \\
& \quad+\left(1-\mu_{0}^{j}\right) \sum_{v^{j} \in V^{j}} \operatorname{Pr}\left(v_{N}^{j} \mid \Phi, \theta=0\right) \times\left(1-I\left(\mu_{N+1}^{j}\left(v_{N}^{j}\right)>0.5\right)\right)
\end{aligned}
$$

Figure 4 illustrates how the total probability of making the correct assessment changes with committee size. ${ }^{42}$ For both sequential and simultaneous voting, the committee is more likely to make the correct assessment as more members are added. The informational gain of adding more committee members displays diminishing returns. After around 12 committee members, there are only small gains from expanding committee size.

\section{[Insert Figure 4 here.]}

In all but one case (where $\mathrm{N}=5$ and updating is Bayesian), simultaneous voting outperforms sequential. Committee members can herd in both the correct and incorrect

\footnotetext{
${ }^{42} \mathrm{As}$ in the previous section, we set the parameters to their average values and use a common prior of 0.5 .
} 
direction. Occasional incorrect local herds under sequential voting drive our result that simultaneous voting outperforms sequential voting on average. Incorrect local herds tend to occur in the event that voters with incorrect signals vote early on, causing subsequent herd types to get the wrong idea about the state. This can take the updated beliefs about the state being "yes" above (below) 0.5 when the true state is actually "no" ("yes"). Clearly, local herds also form in the correct direction. In such cases updated beliefs can exceed (fall below) 0.5 faster under sequential voting when the true state is "yes" ("no"). When a local herd forms in the correct direction, as committee size increases, updated beliefs after everyone has voted under simultaneous voting "catch up" with those under sequential voting. However, updated beliefs formed by incorrect local herds, tend to remain divergent from beliefs under simultaneous voting for a wider range of committee sizes and may not be overturned even for very large committees, leading to incorrect assessments.

The deleterious informational consequences of herding are more prominent if belief updating is naïve. In the naïve version, herd types take the preceding votes at face value, thus belief updating may accelerate faster and it is also harder to overturn beliefs that get off on the wrong foot. In the Bayesian version herd types take into account that a preceding vote which breaks a trend (e.g. a no vote after four yes votes) may come from another herd type, which signals that this voter had a very strong signal against the trend. This positive effect is absent in the naïve version where the herd type believes that the "breaking" vote comes from an expressive type with an "average" signal against the trend.

To assess the effect of a counterfactual decrease in information precision we set $\tau$ equal to 1 and hold all other parameters constant. This corresponds to a situation in which experts receive incorrect signals $25 \%$ of the time. As illustrated in Figure 5, the effect of a decrease in information precision is to exacerbate the negative consequences of herd behavior regardless of which type of updating is applied. Finally, we should mention that there are possible parameter values of our model for which sequential voting outperforms simultaneous voting. This stands in contrast to most of the herding literature building 
on a binary signal structure. ${ }^{43}$

[Insert Figure 5 here.]

\section{Conclusion}

In this paper, we use data from FDA committees to estimate the extent and importance of herd behavior under sequential polling of expert recommendations. We find that around half of the committee members are susceptible to herd behavior and might go against their private assessment if the votes from previous experts indicate otherwise. On average, around 9 percent of the sequential votes are actual herd-votes. Temporary committee members invited on an ad hoc basis are more apt towards herding than regular (standing) members.

Considering the consequences of herding on information aggregation we find that simultaneous voting lowers the probability that the committee's overall assessment is misaligned with the state. Further, we find that simultaneous voting performs substantially better than sequential voting if information is imprecise and/or when members do not take into consideration that preceding members may have herded (i.e. members are "naïve").

We believe that our analysis and results are relevant beyond scientific advisory committees: In situations where people are assembled to give their advice or vote on certain questions; from corporate advisory boards and hiring committees to roll call voting by elected representatives in community councils and commissions. The main policy implication of this study is to follow the example of the FDA and substitute sequential voting with simultaneous (electronic) voting.

In future work we intend to explore the mechanisms behind our main findings in more depth. In this regard, diving into the comments and pre-vote discussions from the FDA meeting transcripts using sentiment analysis and text mining could be fruitful (see e.g. the method and techniques applied in Hansen, McMahon, and Prat (2018) concerning policy

\footnotetext{
${ }^{43}$ An exception is Wiedman (2014) who shows that sequential voting may increase information transmission compared to simultaneous voting in a model with binary signals and competent versus incompetent experts.
} 
makers' deliberations in the FOMC). Directly incorporating and testing for reputational or career concerns would be another way in which to extend the present research.

Another array of future research that we plan to undertake is to study the FDA's decision making process, taking into account both the advisory committees and the clinical study by the sponsor company, and the quality of drug approval decisions. To this end, Li and Agha (2015) study the success of peer-review NIH panels and are able to track the merits of NIH funded research (likewise for unfunded NIH applications in Li (2017)). The quality of FDA decisions may be gauged by e.g. considering drug withdrawals, market reactions, or decisions made by other agencies like the European Medicines Agency. 


\section{APPENDICES}

\section{A Seating order}

In this appendix we present descriptive statistics concerning the order in which votes are announced ("seating order") under sequential voting. In Table A1 we split the sample of votes by voter characteristics and calculate summary statistics on seat number for each category. It is evident that different types of committee members, e.g. those with a $\mathrm{PhD}$ or male members, are very spread out in terms of where they sit in the sequence. The average seat position for all groups is between 6 and 7 with a standard deviation of around 4.5. There are no clear clusters of certain types of committee members at start or end of the voting sequence. In Table A2, we focus on the ten most frequent voters. It is evident that even individual committee members are spread out in terms of where they sit and do not always get placed in the same position.

\begin{tabular}{lccccc}
\hline \hline Voter Characteristic & Frequency & Mean Seat & Std. dev. & Min & Max \\
\hline Regular & 2839 & 6.78 & 4.38 & 1 & 28 \\
Temporary & 1080 & 6.91 & 4.80 & 1 & 21 \\
Consumer rep. & 251 & 7.11 & 4.25 & 1 & 22 \\
Patient rep. & 128 & 7.40 & 4.73 & 1 & 21 \\
PhD & 1352 & 6.37 & 4.10 & 1 & 25 \\
Male & 2782 & 6.63 & 4.47 & 1 & 28 \\
COI waiver & 1011 & 6.48 & 3.69 & 1 & 24 \\
All Sequential Votes & 4298 & 6.85 & 4.50 & 1 & 28 \\
\hline \hline
\end{tabular}

Table A1: Summary statistics for seat no. by voter characteristics 


\begin{tabular}{lccccc}
\hline \hline Voter ID & Frequency & Mean Seat & Std. dev. & Min & Max \\
\hline 570 & 62 & 5.10 & 2.29 & 1 & 11 \\
985 & 46 & 8.91 & 3.44 & 2 & 15 \\
1284 & 46 & 5.67 & 3.10 & 1 & 11 \\
539 & 44 & 5.93 & 3.01 & 1 & 11 \\
1141 & 43 & 7.28 & 5.01 & 1 & 18 \\
1051 & 42 & 5.79 & 3.90 & 1 & 14 \\
791 & 40 & 6.00 & 3.75 & 2 & 15 \\
813 & 40 & 7.30 & 2.74 & 3 & 13 \\
981 & 40 & 6.95 & 4.01 & 2 & 17 \\
848 & 38 & 4.87 & 3.08 & 1 & 11 \\
\hline \hline
\end{tabular}

Table A2: Summary statistics for seat no. for 10 most frequent voters 


\section{B Correlation in vote questions part of the same meeting}

In our empirical implementation, we assume that there is an underlying (latent) variable $y_{j}^{*}$ that determines the true state for a voting question $\mathrm{j}$. We specify $y_{j}^{*}=X_{j}^{\prime} \beta+\epsilon_{j}$ such that:

$$
\theta^{j}= \begin{cases}1 & \text { for } y_{j}^{*}>0 \\ 0 & \text { for } y_{j}^{*} \leq 0\end{cases}
$$

We further assume $\epsilon_{j}$ has a standard logistic distribution which implies $\operatorname{Pr}\left(\theta^{j}=1 \mid X\right)=\frac{\exp \left(X_{j^{\prime}} \beta\right)}{1+\exp \left(X_{j}{ }^{\prime} \beta\right)}$.

Given that we can have multiple voting questions taking place on the same day and relating to the same drug (on average 2-3 voting questions per meeting), we may expect correlation in the true state across voting questions that are part of the same meeting.

We can allow for such correlation by introducing an error term at the meeting level $\epsilon_{m}$. We now specify the underlying (latent) variable as $y_{j}^{*}=X_{j}^{\prime} \beta+\left((1-\sigma) \epsilon_{j}+\sigma \epsilon_{m}\right)$. If $\sigma$ is 0 this collapses to the previous specification, as $\sigma$ increases there is more correlation in the true state for voting questions that are part of the same meeting. Given that private signals are state dependent, there will also be more correlation in private signals within a meeting. Assuming $\epsilon_{m}$ follows the standard logistic distribution, the new error term $\left((1-\sigma) \epsilon_{j}+\sigma \epsilon_{m}\right)$ also follows the standard logistic distribution. Hence we still have $\operatorname{Pr}\left(\theta^{j}=1 \mid X\right)=\frac{\exp \left(X_{j}{ }^{\prime} \beta\right)}{1+\exp \left(X_{j}{ }^{\prime} \beta\right)}$.

In our simulations we implement such an error structure by grouping questions into sets of four and drawing the same $\epsilon_{m}$ for the set. We use a $\sigma$ of 0.7 . We find that our estimates of $\beta, \lambda$, and $\tau$ are unbiased and very similar to what they were before introducing the correlation. 


\section{Alternative specification of the prior}

In order to illustrate the robustness of our results to different specifications of the prior, we implement a model where we estimate a prior for each committee meeting i.e. we estimate 327 priors corresponding to the 327 committee meetings in our dataset. In order to ease estimation of a model with so many parameters, we use constrained minimization. We constrain $\lambda, \pi$ and all elements in the vector of common priors $\mu_{0}$ to be between 0 and 1 . We constrain $\tau$ to be between 0 and 5 .

Table C1 provides the main parameter estimates of this model for both the Bayesian and naïve version. As one might expect, estimating a prior for each meetings allows the prior to vary much more across voting questions and so reduces our estimates of $\tau$ and $\lambda$, but not by too much. We now find that $32-39 \%$ of members are herd types.

\begin{tabular}{lccccc}
\hline \hline & \multicolumn{4}{c}{ Baseline } \\
\cline { 2 - 3 } \cline { 5 - 6 } \cline { 5 - 6 } Parameter & \multicolumn{2}{c}{ Bayesian } & & \multicolumn{2}{c}{ Naïve } \\
\cline { 2 - 3 } \cline { 5 - 6 }$\pi$ & 0.32 & 0.04 & & 0.39 & 0.05 \\
$\tau$ & 0.6 & 0.02 & & 0.6 & 0.02 \\
$\tau$ & 1.17 & 0.04 & & 1.15 & 0.04 \\
\hline \hline
\end{tabular}

Table C1: Estimation results 


\section{Additional regressions}

In this appendix we perform additional regressions to shed light on the finding that regular committee members are less likely to vote with present majority under sequential voting. In column 1 we include an indicator variable that takes the value 1 when a committee member is attending a meeting for the first time. We find that first timers are 3 percentage points more likely to vote with the present majority under sequential voting. In column 2 we include the count of meetings that a member has attended and its interaction with Sequential, the effect has the expected sign, the more meetings a member attends the less likely he/she is to vote with majority under sequential voting, however the coefficient is not significant. We collect information on the age of members from Healthgrades.com. We are not able to find the age for all committee members in our sample. In column 3, we re-run the regression in Table 5 column 3 controlling for age where possible. Our result that regular members are less likely to vote with present majority persists when we control for age. 
I(WithMajority) I(WithMajority) I(WithMajority)

\begin{tabular}{|c|c|c|c|}
\hline \multirow[t]{2}{*}{ Sequential } & $0.0312^{* *}$ & $0.0559^{* * *}$ & $0.0690^{* * *}$ \\
\hline & $(0.0130)$ & $(0.0138)$ & $(0.0193)$ \\
\hline \multirow[t]{2}{*}{ First Meeting } & -0.0116 & & \\
\hline & $(0.0122)$ & & \\
\hline \multirow[t]{2}{*}{ First Meeting X Seq. } & $0.0328^{* *}$ & & \\
\hline & $(0.0162)$ & & \\
\hline \multirow[t]{2}{*}{ No. of Meetings } & & 0.00111 & \\
\hline & & $(0.00144)$ & \\
\hline \multirow[t]{2}{*}{ No. of Meetings X Seq. } & & -0.00391 & \\
\hline & & $(0.00270)$ & \\
\hline \multirow[t]{2}{*}{ Regular } & 0.00662 & 0.00670 & 0.0149 \\
\hline & $(0.00955)$ & $(0.00906)$ & $(0.0139)$ \\
\hline \multirow[t]{2}{*}{ Regular X Seq. } & & & $-0.0446^{* *}$ \\
\hline & & & $(0.0203)$ \\
\hline \multirow[t]{2}{*}{ Age } & & & 0.00003 \\
\hline & & & $(0.000572)$ \\
\hline \multirow[t]{2}{*}{ Consumer Rep. } & $-0.0495^{* * *}$ & $-0.0491^{* * *}$ & $-0.144^{* * *}$ \\
\hline & $(0.0188)$ & $(0.0186)$ & $(0.0434)$ \\
\hline \multirow[t]{2}{*}{ Patient Rep. } & -0.0319 & -0.0313 & $-0.319^{* * *}$ \\
\hline & $(0.0204)$ & $(0.0204)$ & $(0.106)$ \\
\hline \multirow[t]{2}{*}{ Seat } & 0.000738 & 0.000750 & 0.00135 \\
\hline & $(0.000991)$ & $(0.000991)$ & $(0.00121)$ \\
\hline \multirow[t]{2}{*}{$\mathrm{PhD}$} & -0.0128 & -0.0129 & -0.00368 \\
\hline & $(0.00879)$ & $(0.00888)$ & $(0.0120)$ \\
\hline \multirow[t]{2}{*}{ Male } & -0.0112 & -0.0117 & -0.00250 \\
\hline & $(0.00851)$ & $(0.00856)$ & $(0.0105)$ \\
\hline \multirow[t]{2}{*}{ COI Waiver } & 0.0135 & 0.0143 & 0.0228 \\
\hline & $(0.0144)$ & $(0.0144)$ & $(0.0170)$ \\
\hline All question-level controls & yes & yes & yes \\
\hline \multirow[t]{2}{*}{ Constant } & $0.719^{* * *}$ & $0.711^{* * *}$ & $0.751^{* * *}$ \\
\hline & $(0.0399)$ & $(0.0395)$ & $(0.0600)$ \\
\hline Observations & 9,231 & 9,231 & 6,046 \\
\hline R-squared & 0.027 & 0.027 & 0.030 \\
\hline
\end{tabular}

Notes: OLS regression. Standard errors in parentheses are robust. $* * * p<0.01, * * p<$

$0.05, * p<0.1$.

Table D1: Additional reduced-form results 


\section{References}

Ackerley, N., J. Eyraud, C. Franz, B. Kissel, and D. Metivier (2009). Financial conflict-of-interest disclosure and voting patterns at FDA advisory committee meetings. Washington, DC: Eastern Research Group.

Allman, E. S., C. Matias, and J. A. Rhodes (2009). Identifiability of parameters in latent structure models with many observed variables. The Annals of Statistics, 3099-3132.

Anderson, L. R. and C. A. Holt (1997). Information cascades in the laboratory. American Economic Review 87(5), 847-862.

Asch, S. E. (1951). Effects of group pressure upon the modification and distortion of judgments. In H. Guetzkow (Ed.), Groups, leadership, and men, pp. 222-236. Pittsburgh: Carnegie Press.

Banerjee, A. V. (1992). A simple model of herd behavior. Quarterly Journal of Economics 107(3), 797-817.

Bernheim, D. B. and C. L. Exley (2015). Understanding conformity: An experimental investigation. Harvard Business School Working Papers.

Bikhchandani, S., D. Hirshleifer, and I. Welch (1992). A theory of fads, fashion, custom, and cultural change as informational cascades. Journal of Political Economy 100(5), 992-1026.

Brennan, G. and P. Pettit (2000). The hidden economy of esteem. Economics and Philosophy 16, 77-98.

Brown, M. B. (2009). Federal advisory committees in the United States: A survey of the political and administrative landscape. Scientific Advice to Policy Making: International Comparison, 17-39.

Bursztyn, L., F. Ederer, B. Ferman, and N. Yuchtman (2014). Understanding mechanisms underlying peer effects: Evidence from a field experiment on financial decisions. Econometrica 82(4), 1273-1301.

Cai, H., Y. Chen, and H. Fang (2009). Observational learning: Evidence from a randomized natural field experiment. American Economic Review $99(3), 864-82$.

Callander, S. (2007). Bandwagons and momentum in sequential voting. Review of Economic Studies $74(3), 653-684$.

Camara, F. and N. Dupuis (2014). Structural estimation of expert strategic bias: The case of movie reviewers. Working paper.

Camara, F. and M. Kyle (2016). Experts and financial ties: Evidence from FDA advisory committees. Working paper.

Cipriani, M. and A. Guarino (2014). Estimating a structural model of herd behavior in financial markets. American Economic Review 104(1), 224-251.

Cooper, J. C. and J. Golec (2017). Conflicts of interest on expert committees: The case of FDA drug advisory committees. Working paper.

Deutsch, M. and H. B. Gerard (1955). A study of normative and informational social influences upon individual judgment. Journal of Abnormal and Social Psychology 51(3), 629. 
Duggan, J. and C. Martinelli (2001). A bayesian model of voting in juries. Games and Economic Behavior 37(2), 259-294.

Eagly, A. H. and L. L. Carli (1981). Sex of researchers and sex-typed communications as determinants of sex differences in influenceability: A meta-analysis of social influence studies. Psychological Bulletin 90(1), 1.

Eyster, E. and M. Rabin (2010). Naive herding in rich-information settings. American Economic Journal: Microeconomics 2(4), 221-43.

Graham, D. J., D. Campen, R. Hui, M. Spence, C. Cheetham, G. Levy, S. Shoor, and W. A. Ray (2005). Risk of acute myocardial infarction and sudden cardiac death in patients treated with cyclo-oxygenase 2 selective and non-selective non-steroidal anti-inflammatory drugs: nested case-control study. The Lancet 365(9458), 475-481.

Graham, J. R. (1999). Herding among investment newsletters: Theory and evidence. Journal of Finance $54(1), 237-268$.

Hansen, S., M. McMahon, and A. Prat (2018). Transparency and deliberation within the fomc: a computational linguistics approach. The Quarterly Journal of Economics 133(2), 801-870.

Hansen, S., M. McMahon, and C. V. Rivera (2014). Preferences or private assessments on a monetary policy committee? Journal of Monetary Economics 67, 16-32.

Hong, H., J. D. Kubik, and A. Solomon (2000). Security analysts' career concerns and herding of earnings forecasts. The Rand Journal of Economics, 121-144.

Iaryczower, M., X. Shi, and M. Shum (2018). Can words get in the way? the effect of deliberation in collective decision making. Journal of Political Economy 126(2), 688-734.

Iaryczower, M. and M. Shum (2012). The value of information in the court: Get it right, keep it tight. American Economic Review 102(1), 202-37.

Knight, B. and N. Schiff (2010). Momentum and social learning in presidential primaries. Journal of Political Economy 118(6), 1110-1150.

Li, D. (2017). Expertise versus bias in evaluation: Evidence from the nih. American Economic Journal: Applied Economics 9(2), 60-92.

Li, D. and L. Agha (2015). Big names or big ideas: Do peer-review panels select the best science proposals? Science 348, 434-438.

Lurie, P. and A. Zieve (2006). Sometimes the silence can be like the thunder: Access to pharmaceutical data at the FDA. Law and Contemporary Problems 69(3), 85-97.

McKelvey, W. and N. H. Kerr (1988). Differences in conformity among friends and strangers. Psychological Reports 62(3), 759-762.

Moffitt, S. L. (2010). Promoting agency reputation through public advice: Advisory committee use in the FDA. The Journal of Politics 72(3), 880-893. 
Moretti, E. (2011). Social learning and peer effects in consumption: Evidence from movie sales. Review of Economic Studies 78(1), 356-393.

Ottaviani, M. and P. Sørensen (2001). Information aggregation in debate: Who should speak first? Journal of Public Economics 81(3), 393-421.

Pham-Kanter, G. (2014). Revisiting financial conflicts of interest in FDA advisory committees. The Milbank Quarterly 92(3), 446-470.

Scharfstein, D. S., J. C. Stein, et al. (1990). Herd behavior and investment. American Economic Review $80(3), 465-479$.

Shiller, R. J. (1995). Conversation, information, and herd behavior. American Economic Review 85(2), $181-185$.

Smith, L. and P. Sørensen (2000). Pathological outcomes of observational learning. Econometrica 68(2), 371-398.

Urfalino, P. and P. Costa (2015). Secret-public voting in FDA advisory committees. In J. Elster (Ed.), Secrecy and Publicity in Votes and Debates, Chapter 8, pp. 165-195. Cambridge: Cambridge University Press.

Weizsäcker, G. (2010). Do we follow others when we should? A simple test of rational expectations. American Economic Review 100(5), 2340-60.

Welch, I. (1992). Sequential sales, learning, and cascades. Journal of Finance 47(2), 695-732.

Wiedman, E. (2014). Good information cascades. Working paper. 


\section{TABLES}

\begin{tabular}{lccc}
\hline \hline & Sequential & Simultaneous & All \\
\hline FDA reviewer score & & & \\
-1 & 37 & 26 & 63 \\
0 & 287 & 293 & 580 \\
1 & 51 & 119 & 170
\end{tabular}

Priority review

Yes

$123 \quad 71 \quad 194$

No

$\begin{array}{lll}252 & 367 & 619\end{array}$

Question type

Efficacy

$\begin{array}{lll}75 & 83 & 158\end{array}$

Other

$153 \quad 120 \quad 273$

Risk v. Benefit

$126 \quad 179 \quad 305$

Safety

$\begin{array}{lll}21 & 56 & 77\end{array}$

Application type

Non-supplementary

$298 \quad 325 \quad 623$

Supplementary

$\begin{array}{lll}77 & 113 & 190\end{array}$

Product category

Drug

$349 \quad 336 \quad 685$

Biologic

$\begin{array}{lll}26 & 102 & 128\end{array}$

Committee

\begin{tabular}{lccc} 
Anesthetic and Life Support & 1 & 13 & 14 \\
Anti Infective & 25 & 37 & 62 \\
Anti Viral & 16 & 16 & 32 \\
Arthritis & 13 & 31 & 44 \\
Cardiovascular and Renal & 76 & 31 & 107 \\
Dermatologic and Ophthalmic & 11 & 17 & 28 \\
Endocrinologic and Metabolic & 61 & 43 & 104 \\
Gastrointestinal & 24 & 44 & 68 \\
Medical Imaging & 2 & 3 & 5 \\
Nonprescription & 5 & 7 & 12 \\
Oncologic & 70 & 36 & 106 \\
Peripheral and Central Nervous System & 20 & 42 & 62 \\
Psychopharmacologic & 14 & 42 & 56 \\
Pulmonary Allergy & 16 & 49 & 65 \\
Reproductive Health & 21 & 27 & 48 \\
& & & \\
Total & 375 & 438 & 813 \\
\hline
\end{tabular}

Table 1: Voting question characteristics 


\begin{tabular}{|c|c|c|c|}
\hline & Sequential & Simultaneous & All \\
\hline \multicolumn{4}{|l|}{ Type } \\
\hline Regular member & $2839(66 \%)$ & $2878(47 \%)$ & $5717(54 \%)$ \\
\hline Temporary member & $1080(25 \%)$ & $2549(41 \%)$ & $3629(35 \%)$ \\
\hline Consumer representative & $251(6 \%)$ & $372(6 \%)$ & $623(6 \%)$ \\
\hline Patient representative & $128(3 \%)$ & $369(6 \%)$ & $497(5 \%)$ \\
\hline \multicolumn{4}{|l|}{ Degree } \\
\hline Medical & $2579(60 \%)$ & $3581(58 \%)$ & $6160(59 \%)$ \\
\hline $\mathrm{PhD}$ & $1352(31 \%)$ & $1808(29 \%)$ & $3160(30 \%)$ \\
\hline Other degree & $259(6 \%)$ & $395(7 \%)$ & $654(6 \%)$ \\
\hline No degree & $108(3 \%)$ & $384(6 \%)$ & $492(5 \%)$ \\
\hline \multicolumn{4}{|l|}{ Conflict of Interest } \\
\hline Yes & $1011(24 \%)$ & $82(1 \%)$ & $1093(10 \%)$ \\
\hline No & $3287(76 \%)$ & $6086(99 \%)$ & $9373(90 \%)$ \\
\hline \multicolumn{4}{|l|}{ Gender } \\
\hline Male & $2782(65 \%)$ & $4081(66 \%)$ & $6863(66 \%)$ \\
\hline Female & $1516(35 \%)$ & $2087(34 \%)$ & $3603(34 \%)$ \\
\hline Total & 4298 & 6168 & 10466 \\
\hline
\end{tabular}

Table 2: Voter characteristics

\begin{tabular}{lccccccccc}
\hline \hline & & & & & & \multicolumn{3}{c}{ Mean by Voting Rule } \\
\cline { 7 - 10 } Variable & Obs. & Mean & Std. Dev. & Min & Max & Sequential & Simultaneous & Difference \\
\hline Unamimous & 813 & 0.375 & 0.484 & 0 & 1 & 0.477 & 0.288 & $-0.19^{* * *}$ \\
Majority size & 813 & 0.853 & 0.154 & 0.5 & 1 & 0.871 & 0.838 & $-0.033^{* * *}$ \\
Percent yes & 813 & 0.637 & 0.36 & 0 & 1 & 0.664 & 0.614 & $-0.05^{*}$ \\
\hline \hline
\end{tabular}

Notes: $* * * p<0.01, * * p<0.05, * p<0.1$.

Table 3: Descriptive statistics for vote outcomes 


\begin{tabular}{lccccc}
\hline \hline Variable & Frequency & Mean & Std. dev. & Min & Max \\
\hline$I\left(v_{i}^{j}=v_{i-1}^{j}\right)$ & 9653 & 0.787 & 0.41 & 0 & 1 \\
$I$ (WithMajority $)$ & 9231 & 0.83 & 0.376 & 0 & 1 \\
$I\left(v_{i}^{j}=\right.$ yes $)$ & 10466 & 0.633 & 0.482 & 0 & 1 \\
Seat & 10466 & 7.54 & 4.766 & 1 & 28 \\
Size & 10466 & 14.08 & 4.34 & 5 & 28 \\
Share COI & 10466 & 0.104 & 0.171 & 0 & 1 \\
\hline \hline
\end{tabular}

Table 4: Summary statistics 


\begin{tabular}{|c|c|c|c|c|c|c|}
\hline & \multicolumn{6}{|c|}{ Dependent variable } \\
\hline & (1) & (2) & (3) & (4) & (5) & (6) \\
\hline & $I\left(v_{i}^{j}=v_{i-1}^{j}\right)$ & $I\left(v_{i}^{j}=v_{i-1}^{j}\right)$ & I(WithMajority) & $I$ (WithMajority) & $I\left(v_{i}^{j}=y e s\right)$ & $I\left(v_{i}^{j}=y e s\right)$ \\
\hline \multirow[t]{2}{*}{ Sequential } & $0.0633^{* * *}$ & $0.0492^{*}$ & $0.0451^{* * *}$ & $0.0652^{* *}$ & $0.0572^{* * *}$ & 0.0459 \\
\hline & $(0.0121)$ & $(0.0276)$ & $(0.0114)$ & $(0.0258)$ & $(0.0138)$ & $(0.0296)$ \\
\hline \multirow[t]{2}{*}{ Size/10 } & 0.00657 & 0.00436 & 0.00198 & -0.000915 & -0.00444 & -0.00330 \\
\hline & $(0.0134)$ & $(0.0134)$ & $(0.0125)$ & $(0.0125)$ & $(0.0144)$ & $(0.0144)$ \\
\hline \multirow[t]{2}{*}{ FDA Reviewer Score $=-1$} & $-0.0971 * * *$ & $-0.0976^{* * *}$ & $-0.0649 * * *$ & $-0.0671^{* * *}$ & $-0.144^{* * *}$ & $-0.144^{* * *}$ \\
\hline & $(0.0190)$ & $(0.0190)$ & $(0.0182)$ & $(0.0182)$ & $(0.0199)$ & $(0.0199)$ \\
\hline \multirow[t]{2}{*}{ FDA Reviewer Score $=1$} & $0.0710^{* * *}$ & $0.0711^{* * *}$ & $0.0717^{* * *}$ & $0.0718^{* * *}$ & $0.183^{* * *}$ & $0.183^{* * *}$ \\
\hline & $(0.0113)$ & $(0.0113)$ & $(0.0104)$ & $(0.0104)$ & $(0.0122)$ & $(0.0122)$ \\
\hline \multirow[t]{2}{*}{ Priority } & -0.00421 & -0.00534 & -0.00926 & -0.0109 & $0.119^{* * *}$ & $0.121^{* * *}$ \\
\hline & $(0.0107)$ & $(0.0107)$ & $(0.0101)$ & $(0.0101)$ & $(0.0114)$ & $(0.0114)$ \\
\hline \multirow[t]{2}{*}{ Share COI } & 0.0302 & 0.0318 & $0.0564^{*}$ & $0.0535^{*}$ & 0.0633 & 0.0655 \\
\hline & $(0.0334)$ & $(0.0337)$ & $(0.0308)$ & $(0.0311)$ & $(0.0419)$ & $(0.0420)$ \\
\hline \multirow[t]{2}{*}{ Supplementary } & 0.0144 & 0.0138 & 0.0144 & 0.0152 & -0.00811 & -0.00929 \\
\hline & $(0.0107)$ & $(0.0108)$ & $(0.0101)$ & $(0.0101)$ & $(0.0120)$ & $(0.0120)$ \\
\hline \multirow[t]{2}{*}{ Biologic } & 0.0192 & 0.0186 & 0.0188 & 0.0179 & $0.0432^{* * *}$ & $0.0434^{* * *}$ \\
\hline & $(0.0137)$ & $(0.0137)$ & $(0.0130)$ & $(0.0130)$ & $(0.0156)$ & $(0.0156)$ \\
\hline \multirow[t]{2}{*}{ Seat } & -0.000200 & -0.00146 & 0.000738 & -0.000155 & -0.000447 & 0.000198 \\
\hline & $(0.00104)$ & $(0.00129)$ & $(0.000991)$ & $(0.00124)$ & $(0.00107)$ & $(0.00128)$ \\
\hline \multirow[t]{2}{*}{ Regular } & -0.00792 & -0.00158 & 0.00651 & $0.0305^{* * *}$ & $-0.0251^{* *}$ & $-0.0267^{* *}$ \\
\hline & $(0.00942)$ & $(0.0121)$ & $(0.00886)$ & $(0.0115)$ & $(0.0104)$ & $(0.0129)$ \\
\hline \multirow[t]{2}{*}{ Patient Rep. } & $-0.0572 * * *$ & $-0.0487^{*}$ & -0.0312 & -0.0113 & $0.0547^{* *}$ & $0.0476^{*}$ \\
\hline & $(0.0220)$ & $(0.0261)$ & $(0.0204)$ & $(0.0242)$ & $(0.0221)$ & $(0.0264)$ \\
\hline \multirow[t]{2}{*}{ Consumer Rep. } & $-0.0333^{*}$ & $-0.0481^{*}$ & $-0.0489^{* * *}$ & $-0.0506^{* *}$ & $-0.0859^{* * *}$ & $-0.129^{* * *}$ \\
\hline & $(0.0190)$ & $(0.0250)$ & $(0.0186)$ & $(0.0246)$ & $(0.0211)$ & $(0.0268)$ \\
\hline \multirow[t]{2}{*}{$\mathrm{PhD}$} & -0.00736 & -0.0156 & -0.0129 & -0.0193 & -0.0146 & $-0.0232^{*}$ \\
\hline & $(0.00929)$ & $(0.0125)$ & $(0.00878)$ & $(0.0118)$ & $(0.0102)$ & $(0.0133)$ \\
\hline \multirow[t]{2}{*}{ Male } & 0.00266 & 0.0108 & -0.0107 & -0.00795 & -0.00286 & -0.00802 \\
\hline & $(0.00911)$ & $(0.0123)$ & $(0.00850)$ & $(0.0115)$ & $(0.0100)$ & $(0.0131)$ \\
\hline \multirow[t]{2}{*}{ COI Waiver } & 0.0220 & 0.0293 & 0.0128 & 0.0166 & 0.00230 & $0.0849^{*}$ \\
\hline & $(0.0155)$ & $(0.0436)$ & $(0.0144)$ & $(0.0419)$ & $(0.0175)$ & $(0.0498)$ \\
\hline \multirow[t]{2}{*}{ Seat X Seq. } & & $0.00367^{*}$ & & 0.00285 & & -0.00200 \\
\hline & & $(0.00192)$ & & $(0.00180)$ & & $(0.00208)$ \\
\hline \multirow[t]{2}{*}{ Regular X Seq. } & & -0.0160 & & $-0.0675^{* * *}$ & & 0.0105 \\
\hline & & $(0.0189)$ & & $(0.0174)$ & & $(0.0214)$ \\
\hline \multirow[t]{2}{*}{ Patient Rep. X Seq. } & & -0.0328 & & $-0.0763^{*}$ & & 0.0222 \\
\hline & & $(0.0489)$ & & $(0.0451)$ & & $(0.0490)$ \\
\hline Consumer Rep. X Seq. & & 0.0314 & & -0.0106 & & $0.115^{* * *}$ \\
\hline & & $(0.0381)$ & & $(0.0372)$ & & $(0.0433)$ \\
\hline PhD X Seq. & & 0.0220 & & 0.0186 & & 0.0175 \\
\hline & & $(0.0185)$ & & $(0.0175)$ & & $(0.0208)$ \\
\hline Male X Seq. & & -0.0195 & & -0.00704 & & 0.0137 \\
\hline & & $(0.0182)$ & & $(0.0170)$ & & $(0.0203)$ \\
\hline COI X Seq & & -0.00590 & & -0.00007 & & $-0.0920^{*}$ \\
\hline & & $(0.0459)$ & & $(0.0439)$ & & $(0.0524)$ \\
\hline Question Type & yes & yes & yes & yes & yes & yes \\
\hline Topical Committee & yes & yes & yes & yes & yes & yes \\
\hline Constant & $0.634^{* * *}$ & $0.642^{* * *}$ & $0.713^{* * *}$ & $0.713^{* * *}$ & $0.341^{* * *}$ & $0.346^{* * *}$ \\
\hline & $(0.0418)$ & $(0.0431)$ & $(0.0394)$ & $(0.0408)$ & $(0.0420)$ & $(0.0432)$ \\
\hline Observations & 9,653 & 9,653 & 9,231 & 9,231 & 10,466 & 10,466 \\
\hline R-squared & 0.032 & 0.032 & 0.026 & 0.028 & 0.082 & 0.083 \\
\hline
\end{tabular}

Notes: OLS regression. Standard errors in parentheses are robust. $* * * p<0.01, * * p<0.05, * p<0.1$.

Table 5: Reduced-form results 


\begin{tabular}{|c|c|c|c|c|c|c|c|c|c|}
\hline \multirow[b]{3}{*}{ Parameter } & \multicolumn{4}{|c|}{ Baseline } & \multirow[b]{3}{*}{ Parameter } & \multicolumn{4}{|c|}{ Heterogeneity } \\
\hline & \multicolumn{2}{|c|}{ Bayesian } & \multicolumn{2}{|c|}{ Naïve } & & \multicolumn{2}{|c|}{ Bayesian } & \multicolumn{2}{|c|}{ Naïve } \\
\hline & Estimate & $\mathrm{SE}$ & Estimate & $\mathrm{SE}$ & & Estimate & SE & Estimate & SE \\
\hline \multirow[t]{7}{*}{$\lambda$} & 0.48 & 0.04 & 0.52 & 0.04 & $\gamma_{\text {reg }}$ & 0.38 & 0.06 & 0.46 & 0.06 \\
\hline & & & & & $\gamma_{t e m p}$ & 0.55 & 0.07 & 0.67 & 0.07 \\
\hline & & & & & $\gamma_{\text {cons }}$ & 0.45 & 0.10 & 0.51 & 0.09 \\
\hline & & & & & $\gamma_{\text {pat }}$ & 0.32 & 0.15 & 0.35 & 0.14 \\
\hline & & & & & $\gamma_{p h d}$ & 0.06 & 0.06 & -0.01 & 0.06 \\
\hline & & & & & $\gamma_{C O I}$ & 0.16 & 0.06 & 0.11 & 0.06 \\
\hline & & & & & $\gamma_{\text {male }}$ & 0.00 & 0.06 & -0.04 & 0.05 \\
\hline \multirow[t]{7}{*}{$\pi$} & 0.58 & 0.02 & 0.59 & 0.03 & $\alpha_{r e g}$ & 0.58 & 0.03 & 0.58 & 0.03 \\
\hline & & & & & $\alpha_{t e m p}$ & 0.56 & 0.03 & 0.57 & 0.03 \\
\hline & & & & & $\alpha_{\text {cons }}$ & 0.67 & 0.03 & 0.69 & 0.03 \\
\hline & & & & & $\alpha_{\text {pat. }}$ & 0.49 & 0.03 & 0.50 & 0.03 \\
\hline & & & & & $\alpha_{p h d}$ & 0.04 & 0.01 & 0.03 & 0.01 \\
\hline & & & & & $\alpha_{C O I}$ & -0.01 & 0.02 & -0.01 & 0.02 \\
\hline & & & & & $\alpha_{\text {male }}$ & 0.00 & 0.01 & -0.01 & 0.01 \\
\hline \multirow[t]{7}{*}{$\tau$} & 1.26 & 0.03 & 1.28 & 0.03 & $\eta_{\text {reg }}$ & 1.38 & 0.07 & 1.36 & 0.07 \\
\hline & & & & & $\eta_{t e m p}$ & 1.24 & 0.07 & 1.24 & 0.07 \\
\hline & & & & & $\eta_{\text {cons }}$ & 1.09 & 0.10 & 1.14 & 0.11 \\
\hline & & & & & $\eta_{\text {pat. }}$ & 1.12 & 0.10 & 1.12 & 0.10 \\
\hline & & & & & $\eta_{p h d}$ & -0.09 & 0.06 & -0.08 & 0.06 \\
\hline & & & & & $\eta_{C O I}$ & -0.10 & 0.11 & -0.06 & 0.10 \\
\hline & & & & & $\eta_{\text {male }}$ & 0.03 & 0.06 & 0.06 & 0.06 \\
\hline$\beta_{\text {score }=1, \text { priority }, \text { drug }}$ & 1.64 & 0.17 & 1.61 & 0.17 & $\beta_{\text {score }=1, \text { priority }, \text { drug }}$ & 1.67 & 0.17 & 1.58 & 0.17 \\
\hline$\beta_{\text {score }=0, \text { priority }, d r u g}$ & 0.75 & 0.11 & 0.65 & 0.13 & $\beta_{\text {score }=0, \text { priority }, d r u g}$ & 0.73 & 0.11 & 0.63 & 0.12 \\
\hline$\beta_{\text {score }=-1, \text { priority }, \text { drug }}$ & -0.26 & 0.22 & -0.24 & 0.22 & $\beta_{\text {score }=-1, \text { priority }, \text { drug }}$ & -0.25 & 0.22 & -0.24 & 0.23 \\
\hline$\beta_{\text {score }=1, \text { drug }}$ & 1.09 & 0.12 & 1.12 & 0.12 & $\beta_{\text {score }=1, \text { drug }}$ & 1.10 & 0.12 & 1.13 & 0.12 \\
\hline$\beta_{\text {score }=0, \text { drug }}$ & 0.42 & 0.09 & 0.48 & 0.09 & $\beta_{\text {score }=0, \text { drug }}$ & 0.43 & 0.09 & 0.48 & 0.09 \\
\hline$\beta_{\text {score }=-1, \text { drug }}$ & 0.00 & 0.15 & 0.05 & 0.15 & $\beta_{\text {score }=-1, \text { drug }}$ & 0.06 & 0.15 & 0.11 & 0.15 \\
\hline$\beta_{\text {score }=1, \text { biologic }}$ & 0.22 & 0.17 & 0.24 & 0.17 & $\beta_{\text {score }=1, \text { biologic }}$ & 0.24 & 0.17 & 0.26 & 0.17 \\
\hline$\beta_{\text {score }=0, \text { biologic }}$ & 0.46 & 0.11 & 0.51 & 0.11 & $\beta_{\text {score }=0, \text { biologic }}$ & 0.47 & 0.11 & 0.52 & 0.11 \\
\hline$\beta_{\text {score }=-1, \text { biologic }}$ & 0.33 & 0.25 & 0.35 & 0.25 & $\beta_{\text {score }=-1, \text { biologic }}$ & 0.34 & 0.25 & 0.35 & 0.25 \\
\hline
\end{tabular}

Table 6: Estimation results 


\begin{tabular}{|c|c|c|c|c|c|c|}
\hline & \multicolumn{2}{|c|}{$\mu_{0}=0.5$} & \multicolumn{2}{|c|}{$\mu_{0}=0.65$} & \multicolumn{2}{|c|}{$\mu_{0}=0.8$} \\
\hline & Seq. & Sim. & Seq. & Sim. & Seq. & Sim \\
\hline Proportion of herd votes & $8.9 \%$ & NA & $8.2 \%$ & NA & $8.4 \%$ & NA \\
\hline Proportion of unanimous outcomes & $25 \%$ & $9 \%$ & $28.7 \%$ & $10.1 \%$ & $42.6 \%$ & $28.5 \%$ \\
\hline Average size of the majority & 0.88 & 0.8 & 0.89 & 0.82 & 0.88 & 0.82 \\
\hline
\end{tabular}

Notes: $\tau=1.26, \pi=0.58, \lambda=0.48, \mathrm{~N}=13$

Table 7: Simulated outcomes with Bayesian updating

\begin{tabular}{|c|c|c|c|c|c|c|}
\hline & \multicolumn{2}{|c|}{$\mu_{0}=0.5$} & \multicolumn{2}{|c|}{$\mu_{0}=0.65$} & \multicolumn{2}{|c|}{$\mu_{0}=0.8$} \\
\hline & Seq. & Sim. & Seq. & Sim. & Seq. & Sim \\
\hline Proportion of herd votes & $9.8 \%$ & NA & $9.4 \%$ & NA & $6.7 \%$ & NA \\
\hline Proportion of unanimous outcomes & $27.5 \%$ & $10.6 \%$ & $31.3 \%$ & $10.1 \%$ & $54.6 \%$ & $37.4 \%$ \\
\hline Average size of the majority & 0.88 & 0.8 & 0.89 & 0.82 & 0.91 & 0.87 \\
\hline
\end{tabular}

Table 8: Simulated outcomes with naïve updating 


\section{FIGURES}

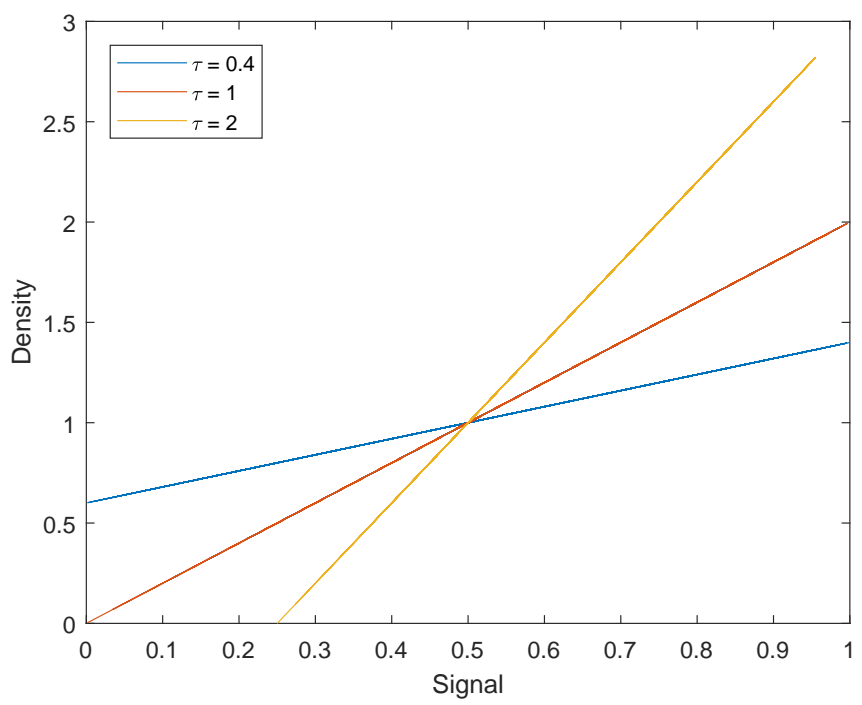

Figure 1: Probability density function of private signals $\mid \theta=1$

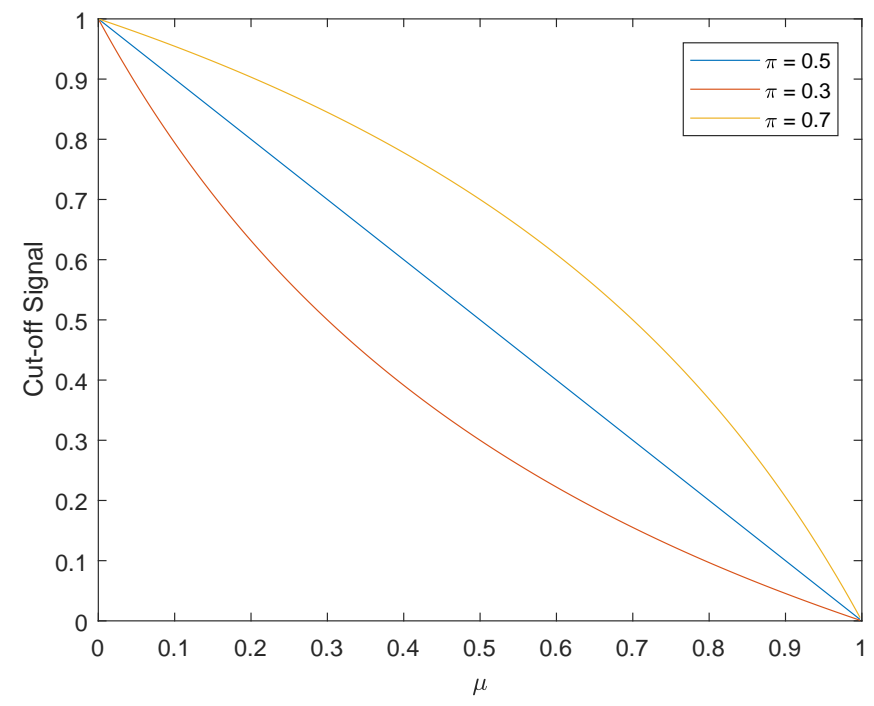

Figure 2: Cut-off signals (illustration with $\tau=1$ ) 



Figure 3: Agreement of votes 


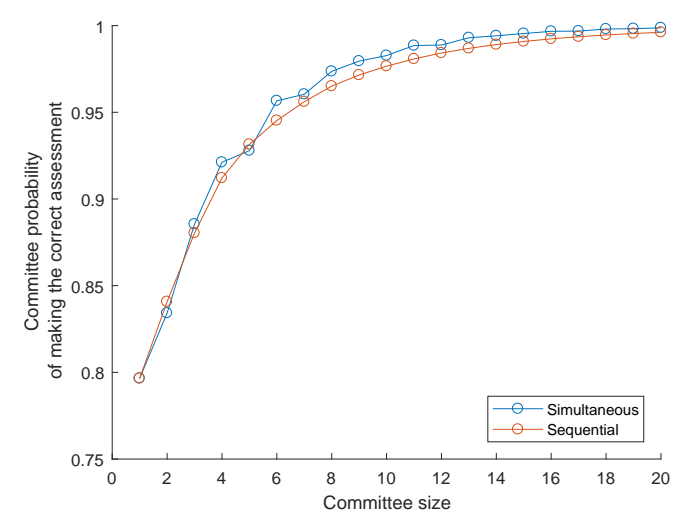

(a) Bayesian updating

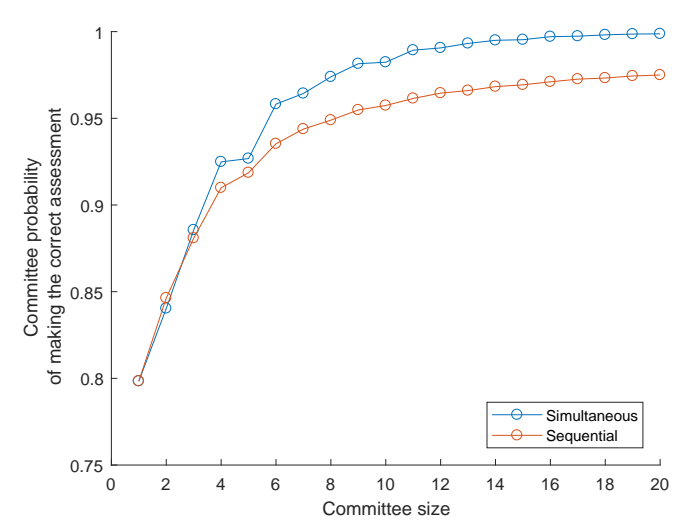

(b) Naïve updating

Figure 4: Information aggregation



(a) Bayesian updating



(b) Naïve updating

Figure 5: Information aggregation with a lower precision of information 